\title{
Observation of the airflow over the Alps during a foehn event
}

\author{
By KLAUS P. HOINKA \\ Institute of Atmospheric Physics, German Aerospace Research Establishment (DFVLR), Oberpfaffenhofen, \\ Federal Republic of Germany
}

(Received 25 January 1984; revised 12 June 1984)

SUMMARY

A detailed analysis is presented of the large-scale, mesoscale and local features of a south-foehn event in the Alps on 8 November 1982. On this day, with a substantial cross-mountain flow, instrumented aircraft made programmed flights back and forth across the Alps between southern Germany and northern Italy. Rawinsonde observations were used to complete the data set. A mesoscale double mountain wave with an amplitude of $1 \mathrm{~km}$ was found in the upper troposphere. In the mid troposphere above the Inn valley a rather pronounced wave with an amplitude of $2 \mathrm{~km}$ and a wavelength of $50 \mathrm{~km}$ was analysed. This wave was close to overturning. The foehn turned out to be accompanied by low wave drag at high levels and with strong wave drag at lower levels. Downward southerly (westerly) momentum flux was evaluated to be $0 \cdot 3(0 \cdot 1) \mathrm{Pa}$. Mountain drag was estimated to be between 1.6 and $6.7 \mathrm{~Pa}$. Light to moderate turbulence was observed immediately to the lee in a low-level turbulence zone over the region of strong gusty surface winds. Finally, special attention has been devoted to the similarities and possible differences between foehn in the Alps and chinook in the Rocky Mountains.

\section{INTRODUCTION}

On approximately 50 days a year strong downslope wind events occur in the northern lee of the Alps; so foehn events have a considerable influence on weather and climate for areas close to the Alps. Foehn is a warm dry gusty wind on the lee side of a mountain range. A foehn occurring on the northern slopes of the Alps is called a south foehn. In order to be able to predict foehn an understanding of the synoptic environment in which these storms build up is required. Knowledge of this environment requires insight into mesoscale-large-scale interactions.

Klemp and Lilly (1975) and Lilly (1978) presented an analysis of the large-scale, mesoscale and turbulence-scale features of a major windstorm event in central Colorado in January 1972. Recently Klemp and Lilly (1978) and Peltier and Clark (1979) have contributed numerical simulations of the same event. The observational and numerical studies have improved our knowledge of strong downslope wind events in the Rocky Mountains. Observations similar to those made above the Rocky Mountains (Klemp and Lilly 1978) or during WAMFLEX (Lilly et al. 1982) are lacking for the troposphere above the Alps. The question is, to what extent are the results obtained from measurements above the Rocky Mountains applicable to foehn-type weather in the Alps?

There are some important differences between the Alps and the Rocky Mountains. The Rocky Mountains act as a north-south barrier in the westerly flow belt; the Alps lie in an east-west direction. The Alps are of smaller dimensions than the Rocky Mountains; in addition we find more mesoscale three-dimensional irregularities in the Alps, which forces the occurrence of phenomena of local character. Another important difference is that the atmosphere above the Rockies is less humid than the Alpine atmosphere. Most of the humidity has rained out on the coastal ranges from California to Washington. Moreover, the surface level where the chinook occurs in Colorado is one mile high, for the Alpine foehn this level is about $600 \mathrm{~m}$. This leads to different background humidity, and according to Durran and Klemp (1982) this should lead to different responses in wave dynamics. The most important difference between chinook and foehn is, however, that the foehn usually occurs as a result of the impact of orography on a pre-frontal atmosphere; this is not so often the case with the chinook in the Rocky 
Mountains. All this suggests that there could and should be differences in the weather between the foehn in the Alps and the chinook in the Rocky Mountains.

One aim of the field experiment ALPEX was to study the dynamical and thermal structure of the troposphere above the Alps during foehn. However, weather conditions during ALPEX were uncooperative in providing foehn events. So, in the autumn of 1982 a field programme took place in southern Germany conducted by the DFVLR to investigate the mesoscale structure of foehn and its interaction with larger scales of motion. On days when substantial cross-mountain wind flow occurred, two twin-engined aircraft, Falcon and Queenair, and three motorized sailplanes made data-gathering flights across the Alps between southern Germany and northern Italy in a layer between $1 \mathrm{~km}$ and $12 \mathrm{~km}$ above m.s.l. Rawinsonde observations along a line perpendicular to the Alps were used to complete the data set. Data were collected on three days in the autumn of 1982. In the present paper a detailed analysis of the large-scale and mesoscale features of the atmosphere during the foehn on 8 November 1982 is presented based on the observations and measurements made by aircraft and by rawinsondes. This analysis has four principal objectives.

Our knowledge of the upper air structure of the Alpine foehn is obviously inadequate. The first objective is therefore to describe the thermal and dynamical structure of the troposphere above the Alps during a strong downslope wind event in the northern lee of the Alps.

Lack of suitable input data for numerical models remains a problem in forecasting the onset, duration and strength of foehn. Klemp and Lilly (1975) emphasized the sensitivity of wave response calculations to details of upstream atmospheric features. Therefore a second objective is to consider the possible upstream conditions necessary for the occurrence of foehn.

The large-scale structures are altered by feedback effects from mesoscale to larger scales in the form of downward momentum transport (Lilly 1972). A third objective is to evaluate as accurately as the data allow the magnitude of the momentum exchange between the atmosphere and the sloping terrain. This is first done using aircraft data. In a second step we compute the loss of energy along isentropes to determine the momentum flux divergences and compare it with energy dissipation estimates from aircraft data. All these evaluations give a rough estimate of the magnitude of the momentum loss of flows over mountains on the scale of the Alps.

As emphasized above there are obvious differences between the two forcing systems of the Alps and the Rocky Mountains. A survey of available literature suggests that both winds exhibit similar surface and upper air characteristics. Thus a fourth objective is to show similarities and possible differences between chinook in the Rocky Mountains and foehn in the Alps.

The synoptic features of the 8 November foehn are examined in detail in section 3. The following section contains the analysis of the mesoscale structure of the mid and upper troposphere. Section 5 discusses the windward side upstream conditions and the basic state properties of the atmosphere for foehn. In the two following sections the momentum flux, energy dissipation and relevant features are examined. In section 8 we make some comments on the stationarity of the event and in the last section we document a moderate turbulent event.

\section{Flight STRATEgIES AND THE DATA}

On 8 November 1982, five instrumented aircraft made data-gathering flights over the Alps between Munich (Germany) and Vicenza (Italy): two twin-engined aircraft, 
the DFVLR jet Falcon and a Queenair, and three motorized sailplanes. A brief description of the experimental set-up is given in Fig. 1. This is a cross-section across the Alps with Vicenza (VIC) located south of the Alps on the left and Munich (MUN) located north of the Alps on the right. The full lines mark the flight tracks of the Falcon, flying back and forth between Munich and Vicenza at an altitude between 6 and $12 \mathrm{~km}$. The dashed lines show the tracks of the Queenair, flying between Munich and the Brenner Pass (BRE), which is the main divide of the Alps. This aircraft made one 'missed approach' extra at Innsbruck (INN) in the Inn valley to get a vertical sounding. The dotted lines indicate the tracks of the three motorized sailplanes, which flew between Munich and the northern baseline of the Alps between 800 and $2500 \mathrm{~m}$. Additionally rawinsonde observations (vertical lines) were available at Munich, Hohenpeissenberg (HOH), Garmisch (GAR), Innsbruck, Milan (MIL) and Udine (UDI).

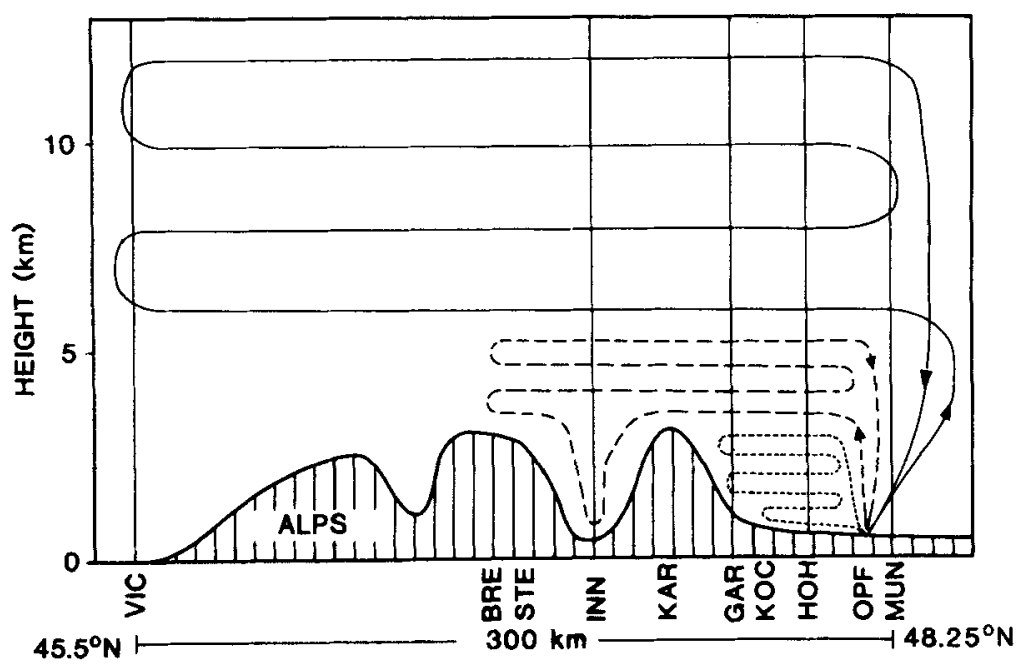

Figure 1. South to north cross-section showing the experimental set-up of the foehn experiment. North Italy with Vicenza (VIC) on the left and South Germany with Munich (MUN) to the right. The abbreviations stand for: BRE (Brenner Pass), STE (Steinach), INN (Innsbruck), KAR (Karwendel mountains), GAR (Garmisch), KOC (Kochel), HOH (Hohenpeissenberg) and OPF (Oberpfaffenhofen). The full lines show the flight tracks of the Falcon; the long (short) dashed lines signify the tracks of the Queenair (motorized sailplanes). Vertical lines show the rawinsonde stations.

Climate studies (Hoinka 1980) show that the basic flow during foehn usually comes from $230^{\circ}$, which would be along a baseline from Milan to Munich (angle of attack of $50^{\circ}$ ). In the present experiment the angle between the main line of the Alps and the cross-sections flown by the aircraft is $90^{\circ}$ (Fig. 2). Due to air traffic control restrictions it was impossible to fly a flight pattern above a baseline Milan-Munich to sample a vertical section through the atmosphere parallel to the jet. 


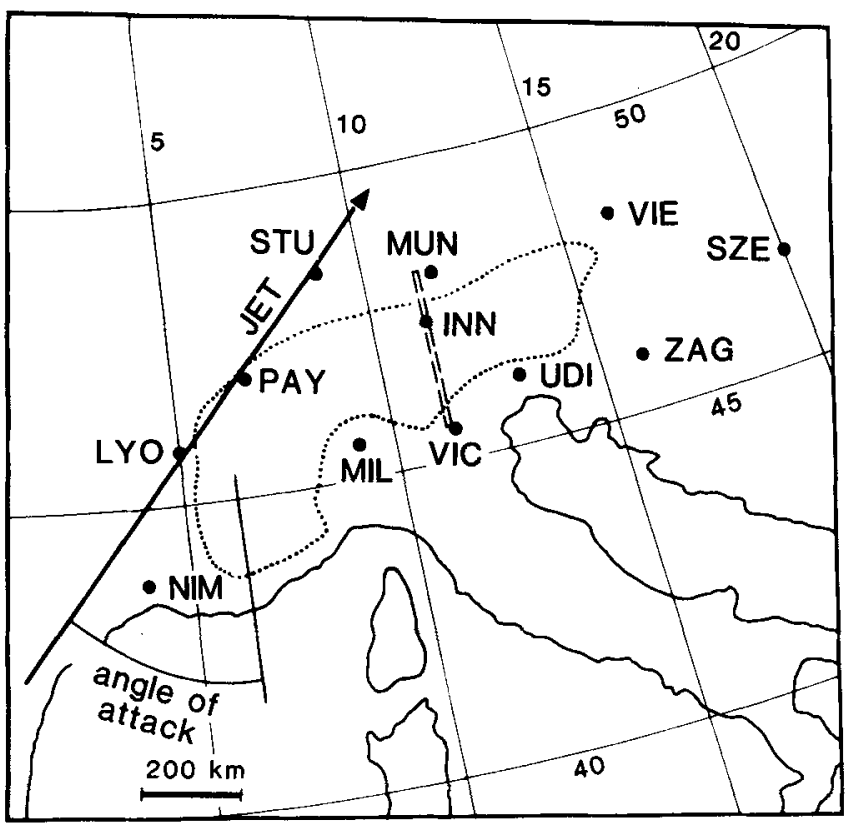

Figure 2. Map of mid Europe with the location of the jet on 8 November 1982. The dashed line shows the location of the cross-section flown. The dotted line indicates the Alps. The abbreviations stand for: LYO (Lyon), NIM (Nimes), MIL (Milan), PAY (Payerne), STU (Stuttgart), UDI (Udine), VIE (Vienna), VIC (Vicenza), ZAG( Zagreb) and SZE (Szeged).

Instrumentation and output data available from the Falcon are described briefly by Hauf (1984). The accuracy of the instrumentation and recorded data is also described to some extent by Hauf. The absolute accuracy of temperature is $0.2 \mathrm{~K}$, of dew-point $1.0 \mathrm{~K}$, of pressure $0.25 \mathrm{mb}$, of the horizontal wind components $1.5 \mathrm{~m} \mathrm{~s}^{-1}$ and of the vertical wind component $0.5 \mathrm{~m} \mathrm{~s}^{-1}$. The relative errors of temperature are $0.05 \mathrm{~K}$, of dew-point $0.05 \mathrm{~K}$, of wind speed $0 \cdot 1 \mathrm{~m} \mathrm{~s}^{-1}$ and of static pressure $0.25 \mathrm{mb}$ (Kennedy 1982). The data of the Falcon are originally $10 \mathrm{~Hz}$ data; after filtering out very high frequencies, more than $1 \mathrm{~Hz}$, averaged values for every second are calculated. Depending on the true ground speed an averaged value over a second is representative for a horizontal distance of approximately $150 \mathrm{~m}$. For the Queenair and the motorized sailplanes the absolute accuracy of temperature is $0.3 \mathrm{~K}$, of dew-point $1.0 \mathrm{~K}$ and of pressure $0.25 \mathrm{mb}$. The relative errors are $0.1 \mathrm{~K}, 0.05 \mathrm{~K}$ and $0.25 \mathrm{mb}$ respectively. For all aircraft types, averaged values over $1 \mathrm{~s}$ were available. Depending on the true ground speed this is representative of a horizontal distance of approximately $50 \mathrm{~m}$ (Queenair) and $30 \mathrm{~m}$ (motorized sailplanes).

\section{THE SYNOPTIC ENVIRONMENT}

Figure 3, top, shows the synoptic situation at $700 \mathrm{mb}$ on 8 November. There is a trough over the east Atlantic and a ridge of high pressure above east Europe, leading to south-westerly flows above the Alps in the mid to upper troposphere. The strong advection of warm air from the SW, typical for south-foehn events, can be seen clearly in Fig. 4, where the thickness chart $(500-1000 \mathrm{mb})$ is plotted. Note the block of cold air at the southern windward side above northern Italy. 

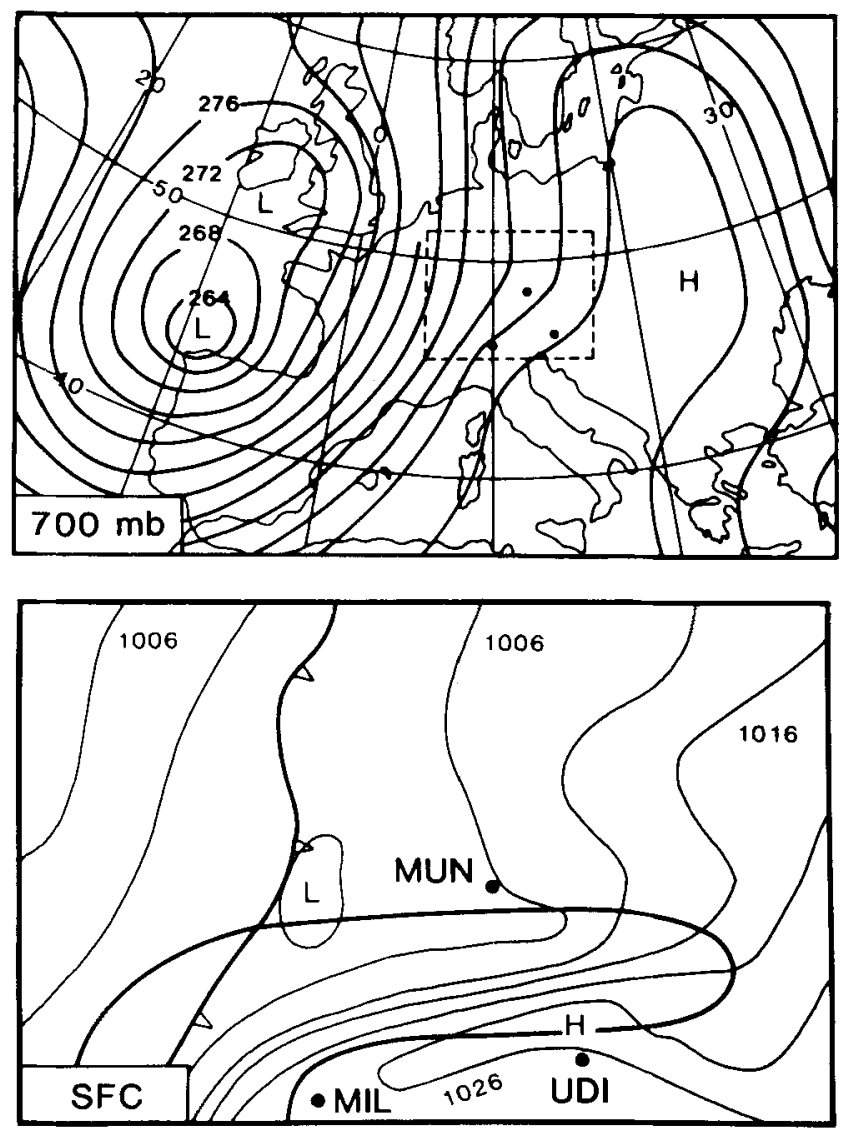

Figure 3. $700 \mathrm{mb}$ chart and surface chart for 8 November 1982. The enlarged part of the surface chart is indicated by the rectangular area in the $700 \mathrm{mb}$ chart. The front is indicated by triangles. The heavy line between MUN, MIL and UDI indicates the Alps.

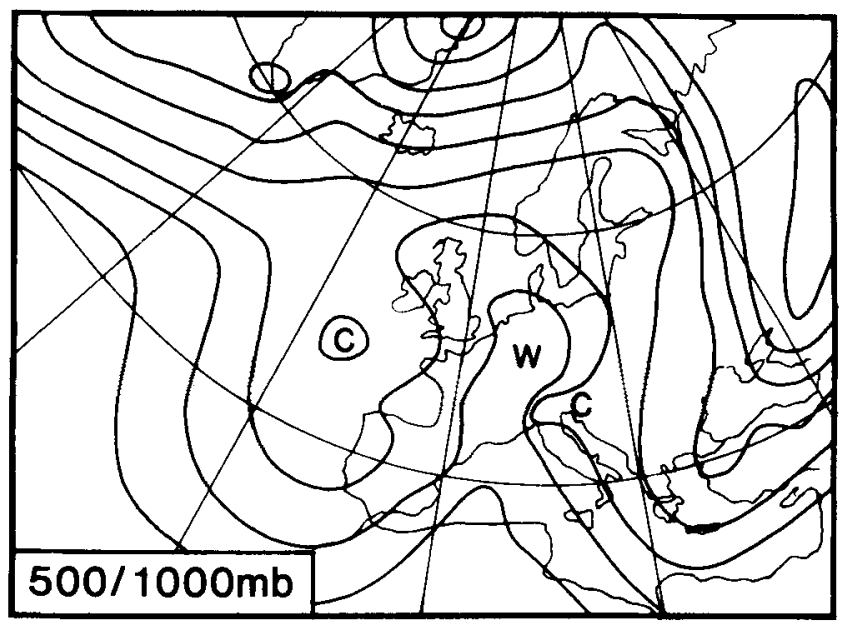

Figure 4. Thickness chart on 8 November $12 \mathrm{GMT}$. 
In Fig. 3, bottom, the rectangle in the centre of the upper figure is enlarged. It shows the surface m.s.l. pressure distribution across the Alps. There is a significant mesoscale lee trough and a ridge of high pressure on the windward side. A pressure gradient of approximately $10 \mathrm{mb}$ per $100 \mathrm{~km}$ can be seen across the Alps. The climatic pressure gradient for foehn occurrence is $2.1 \mathrm{mb}$ per $100 \mathrm{~km}$ (Hoinka 1980) and for chinook $4.7 \mathrm{mb} / 100 \mathrm{~km}$ across the Rockies (Brinkmann 1974). The magnitude of the observed gradient during the present foehn event suggests that this was a very intense example of foehn.

Parts of the strong pressure gradient can be explained by the observed stagnation of cold air on the windward side of the mountain range. Assuming that at about summit level the pressure gradients across the barrier vanish, the surface pressure difference due to different air masses on the two sides of the Alps can be estimated by

$$
\Delta p_{\mathrm{s}}=-\left(h g \bar{p}_{\mathrm{s}} / R \bar{T}^{2}\right) \Delta T .
$$

Here $p_{\mathrm{s}}$ is the surface pressure and $T$ the vertical mean temperature in the layer $h$, which is the mountain height. The average over the lee and windward side is signified by an overbar. With $h=3000 \mathrm{~m}, T$ (Milan) $=1{ }^{\circ} \mathrm{C}$ and $T$ (Munich) $=10^{\circ} \mathrm{C}$, we get a surface pressure difference of $12 \cdot 1 \mathrm{mb}$.

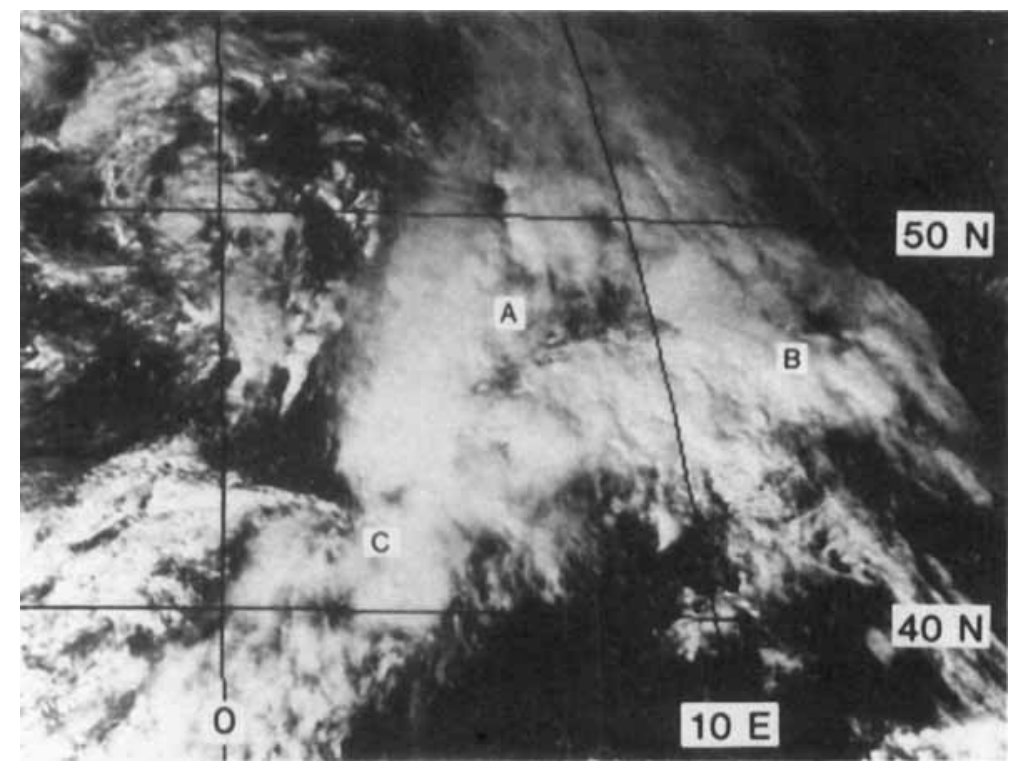

Figure 5. Meteosat image for 8 November $13 \mathrm{GMT}$ (Vis). Switzerland, Salzburg and the Pyrenees are indicated by $\mathrm{A}, \mathrm{B}$ and $\mathrm{C}$ respectively.

The satellite picture (Meteosat-2, Vis., $13 \mathrm{GMT}$ ) given in Fig. 5, shows the cloud cover above Europe. Above and south of the Alps there are low- and high-level clouds. North of the Alps (close to Switzerland) there is an apparent gap in the cloud (A). A similar cloud gap but less clear can be seen above Salzburg (Austria) (B). It should be 
noted that above the eastern edge of the Pyrenees (C) a similar cloud gap in triangular form can be seen. Additionally, low-level clouds are observed at the windward side south of the Pyrenees (very white clouds); these low-level clouds are induced orographically by the blocking of the Pyrenees forcing upgliding and cloud formation. This all goes to indicate that on the leeward sides of the Alps and the Pyrenees a subsidence of air has occurred leading to a decrease in cloudiness. In short, the synoptic structure shows a flow towards the Alps from the SW and therefore mountain wave and foehn features can be expected.
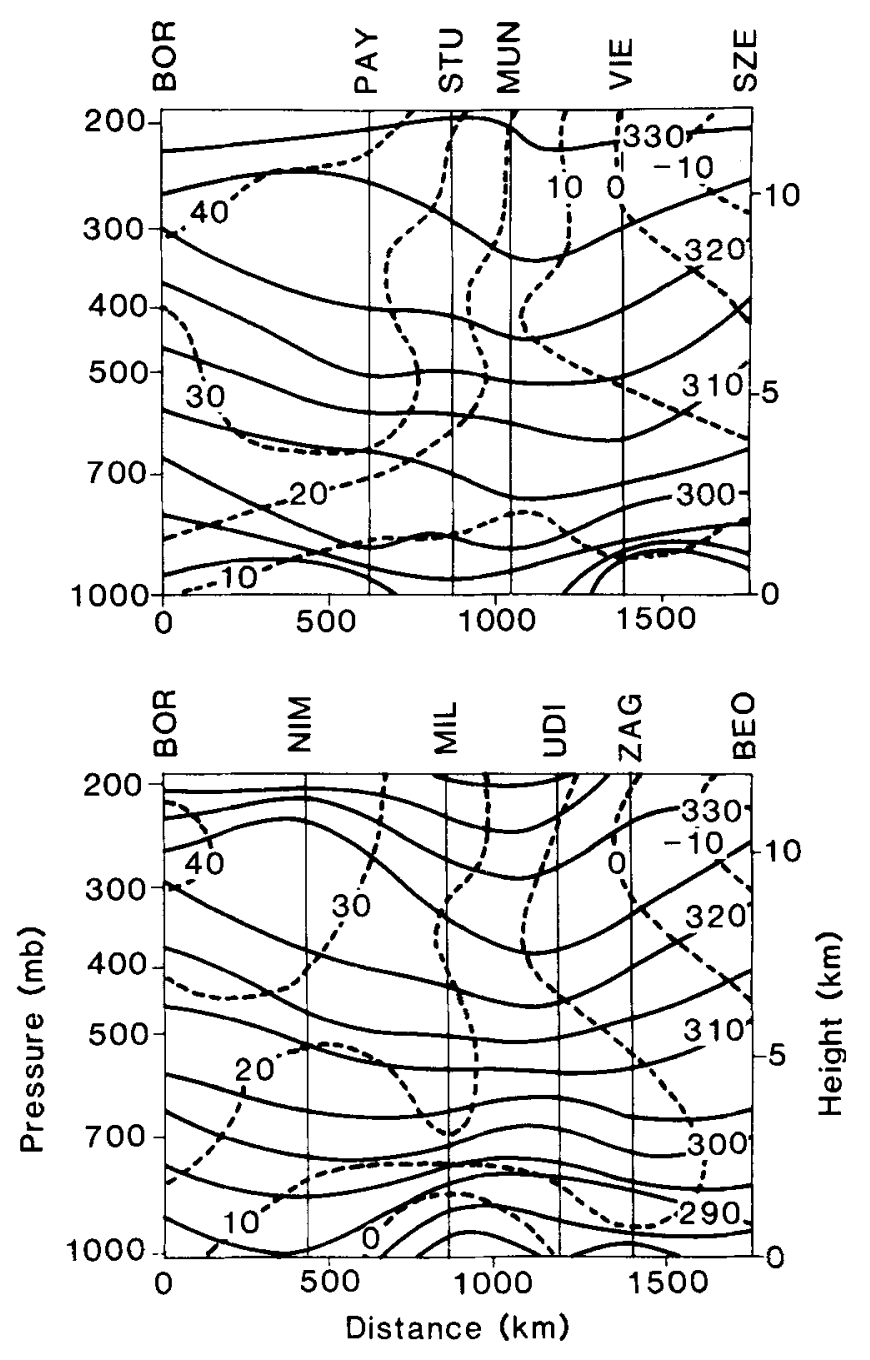

Figure 6. Cross-sectional analysis of potential temperature (full lines) in $\mathrm{K}$ and horizontal south-west wind components (dashed lines) in $\mathrm{m} \mathrm{s}^{-1}$ for 12 GMT 8 November from west to east north of the Alps (top) and south of the Alps (bottom). The top figure shows the northern section from Bordeaux (BOR), PAY (Payerne), STU (Stuttgart). MUN (Munich), VIE (Vienna) to SZE (Szeged). The bottom figure shows the southern section from Bordeaux (BOR), NIM (Nimes), MIL (Milan), UDI (Udine), ZAG (Zagreb) to BEO (Beograd). 
When analysing two-dimensional cross-sections one should pay attention to the natural variation expected transverse to the jet across the barrier. It is a well-known fact that in the case of airflow over mountains the structure of the troposphere is modified above the barrier, leading to different stratification and behaviour at the windward and lee sides. In the present case an isentropic analysis is given in Fig. 6 showing wind and potential temperature of the leeward side atmosphere (top) and the windward side (bottom). Both cross-sections have west on the left and east on the right. We can see the typical opening of the isentropes (full lines) in the jet stream core. The dashed lines show the south-west component of the wind. North of the Alps the eastern edge of the jet with winds greater than $30 \mathrm{~m} / \mathrm{s}$ is located west of Stuttgart (STU) and south of the Alps west of the area between Nimes (NIM) and Milan (MIL). This confirms that the angle of attack of the jet towards the Alps is approximately $45^{\circ}$ (see Fig. 2) which was expected from the gradients of isohypses above the Alps plotted in Fig. 3.
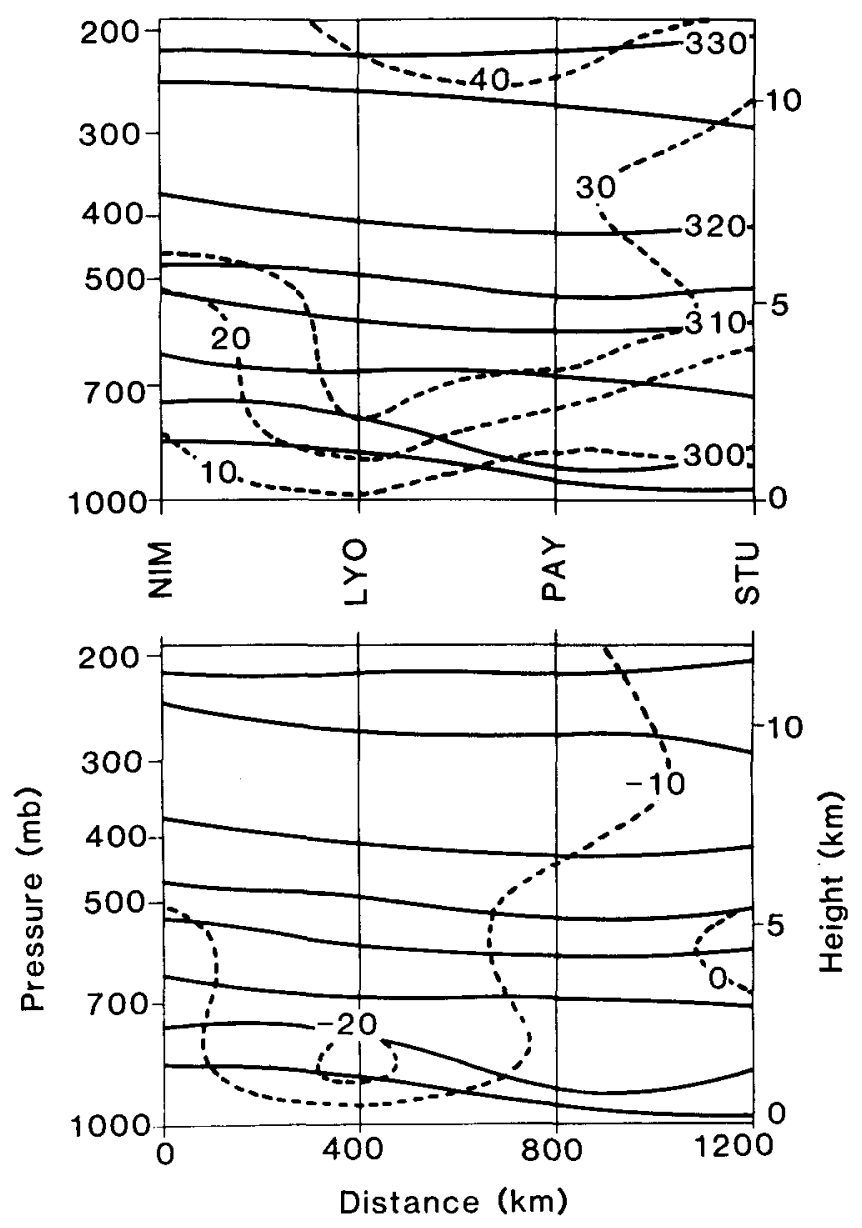

Figure 7. Cross-sectional analysis of potential temperature (full lines) in $\mathbf{K}$ and horizontal wind components (dashed lines) in $\mathrm{m} \mathrm{s}^{-1}$ for $12 \mathrm{GMT} 8$ November along the jet axis from Nimes to Stuttgart. In the top (bottom) figure the south-west (north-west) component of the wind is given. 
Descending isentropes indicate a cold front approaching from the west located north of the Alps between STU and MUN and south of the barrier between NIM and MIL (see Fig. 5). On the lee side the differences of height of the isentropes above the area between STU and VIE are greater than on the windward side (between MIL and ZAG). For example, the difference in height between the $300 \mathrm{~K}$ and the $330 \mathrm{~K}$ isentrope is $7 \mathrm{~km}$ on the windward side (MIL) and $12 \mathrm{~km}$ on the lee side (MUN). This means that the mid troposphere in the lee of the mountain is less stable than the atmosphere on the windward side. Similar lee side destabilization can be observed above the Rockies during strong chinook (Lilly 1978) and during airflow over the Pyrenees (Hoinka 1984).

In Fig. 7 we present an isentropic analysis from NIM to STU. This cross-section lies parallel to the jet in its main core. As expected, the horizontal gradients of potential temperature are weak. In the entire troposphere the main flow comes from the southwest with the exception that in the lower troposphere above LYO we find a strong negative north-westerly component. This indicates that in this area the main flow comes from the south parallel to the Alps. This is an effect of the channelling forced by the Rhone valley as well as of flow splitting, which has occurred at approximately $700 \mathrm{mb}$. Beneath this level there is a flow around the Alps, above it a flow across the barrier. A similar splitting was observed during ALPEX for north-westerly flows (Smith et al. 1982).

\section{THe Mesoscale STRUCTURE}

In the preceding section we pointed out that the jet crossed the barrier at an angle of $45^{\circ}$. As mentioned, there was no possibility of flying parallel to the jet in its main core. Therefore the following isentropic and wind analyses based on the aircraft data should be considered as a rough estimate of the synoptic-scale flow across the Alps. The observed isentropic field and the horizontal wind field are shown in Fig. 8. The crosssection is oriented south to north with south to the left. Thus the flow comes from the left. The isentropic patterns in data-gap regions are estimated by subjective analysis according to the data above and beneath these regions.

A waveless flow approaches the barrier. Above the barrier, between 6 and $12 \mathrm{~km}$ a double wave with a wavelength of $60 \mathrm{~km}$ is analysed. Assuming that the wavenumber vector lies parallel to the jet axis the wavelength reduces to $45 \mathrm{~km}$. The phaselines are tilted vertically upstream, indicating downward flux of horizontal momentum. In the lower troposphere on the lee side a wave pattern is analysed. This mesoscale structure will be discussed in an enlarged diagram which follows. The heights of the isentropes above Milan based on rawinsonde observations are indicated in the figure by circles. On the lee side the differences in height of the isentropes are greater than on the windward side. For example, the difference in height between the $300 \mathrm{~K}$ and the $330 \mathrm{~K}$ isentropes is $7 \mathrm{~km}$ on the windward side and $12 \mathrm{~km}$ on the lee side. This lee side destabilization confirms the rawinsonde analysis in the preceding section.

The crosses in Fig. 8 mark regions with light to moderate turbulence, mostly light. Close to the tropopause turbulence was encountered above the barrier and in the near upstream area. A second separate region with intense turbulence generation occurred above the crest at about $6 \mathrm{~km}$ in the upward motion part of the primary trough. In the lower troposphere moderate turbulence was encountered in the lee region.

The dynamical structure is illustrated in Fig. 8, bottom. A strip of low velocities of $10 \mathrm{~m} \mathrm{~s}^{-1}$ is analysed for the mid troposphere. On the lee side an increase up to $30 \mathrm{~m} \mathrm{~s}^{-1}$ was analysed. Another apparent feature is that the upstream wind velocities in the entire troposphere are significantly smaller than the downstream velocities, indicating that the lee side part of the cross-section was closer to the jet axis than the windward side part. 

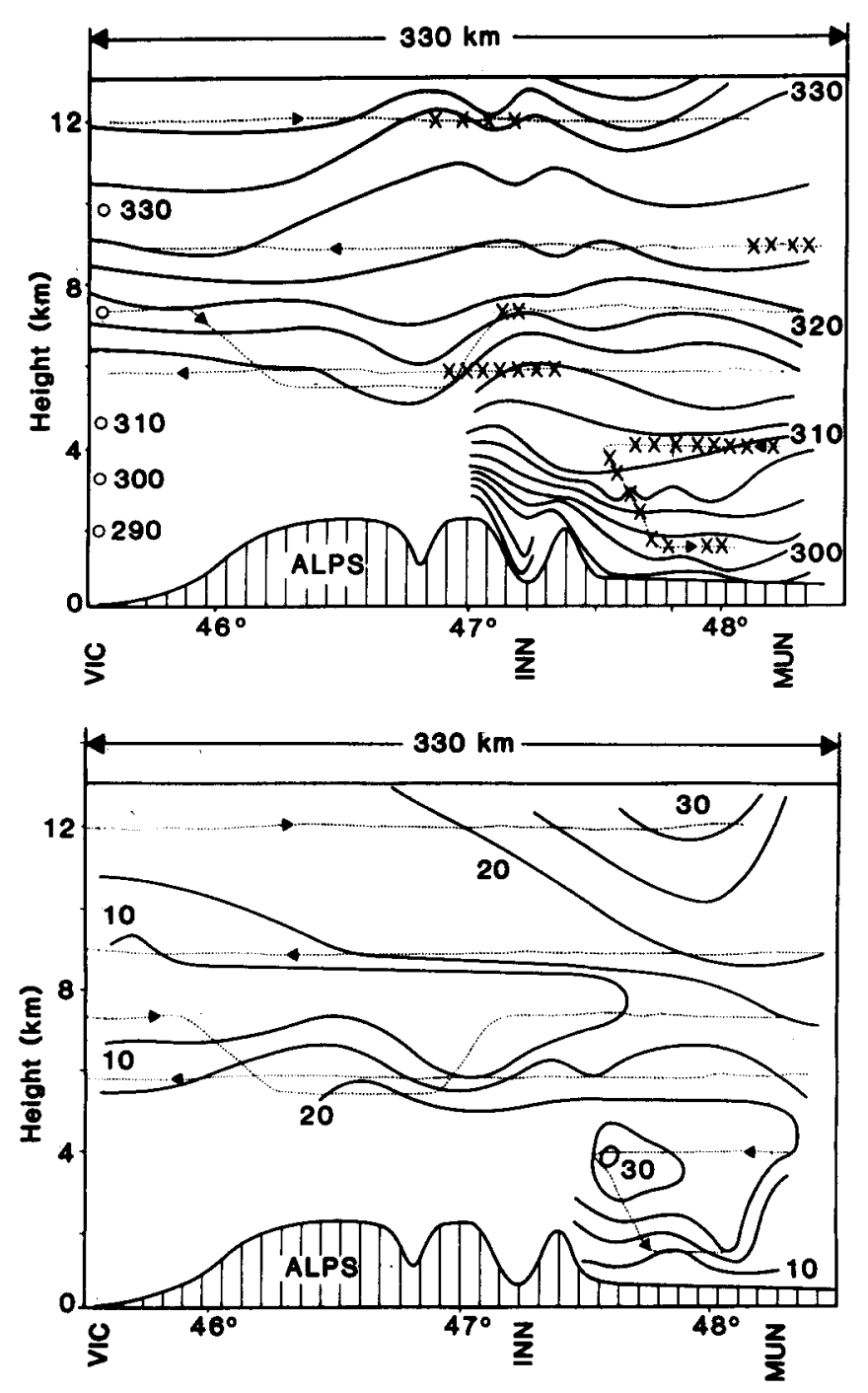

Figure 8. Cross-sections of potential temperatures in $\mathrm{K}$ (top) and south-westerly wind components in $\mathrm{m} \mathrm{s}^{-1}$ (bottom) along a north-south line between VIC and MUN obtained from analysis of the Falcon data on 8 November 1982. The dashed lines indicate the flight legs. The crosses mark regions where light to moderate turbulence was encountered. The circles mark the height of the isentropes above Milan obtained from rawinsonde data.

At the same time gusts up to $25 \mathrm{~m} \mathrm{~s}^{-1}$ were observed at the surface at Innsbruck and up to $55 \mathrm{~m} \mathrm{~s}^{-1}$ at the mountain station Zugspitze. A rough estimate of the surface velocities to be expected can be made by applying the steady-state equation of motion. In this case the pressure gradient term is balanced by the advection term. Using the observed pressure gradient of $20 \mathrm{mb}$ across the Alps we get a downslope wind velocity of $45 \mathrm{~m} \mathrm{~s}^{-1}$. Brinkmann (1974) pointed out that the maximum surface gusts recorded in Boulder during chinook events are frequently stronger than the mean wind speed at any level in the troposphere upstream of the mountain. This feature can be seen clearly during the present foehn event. 

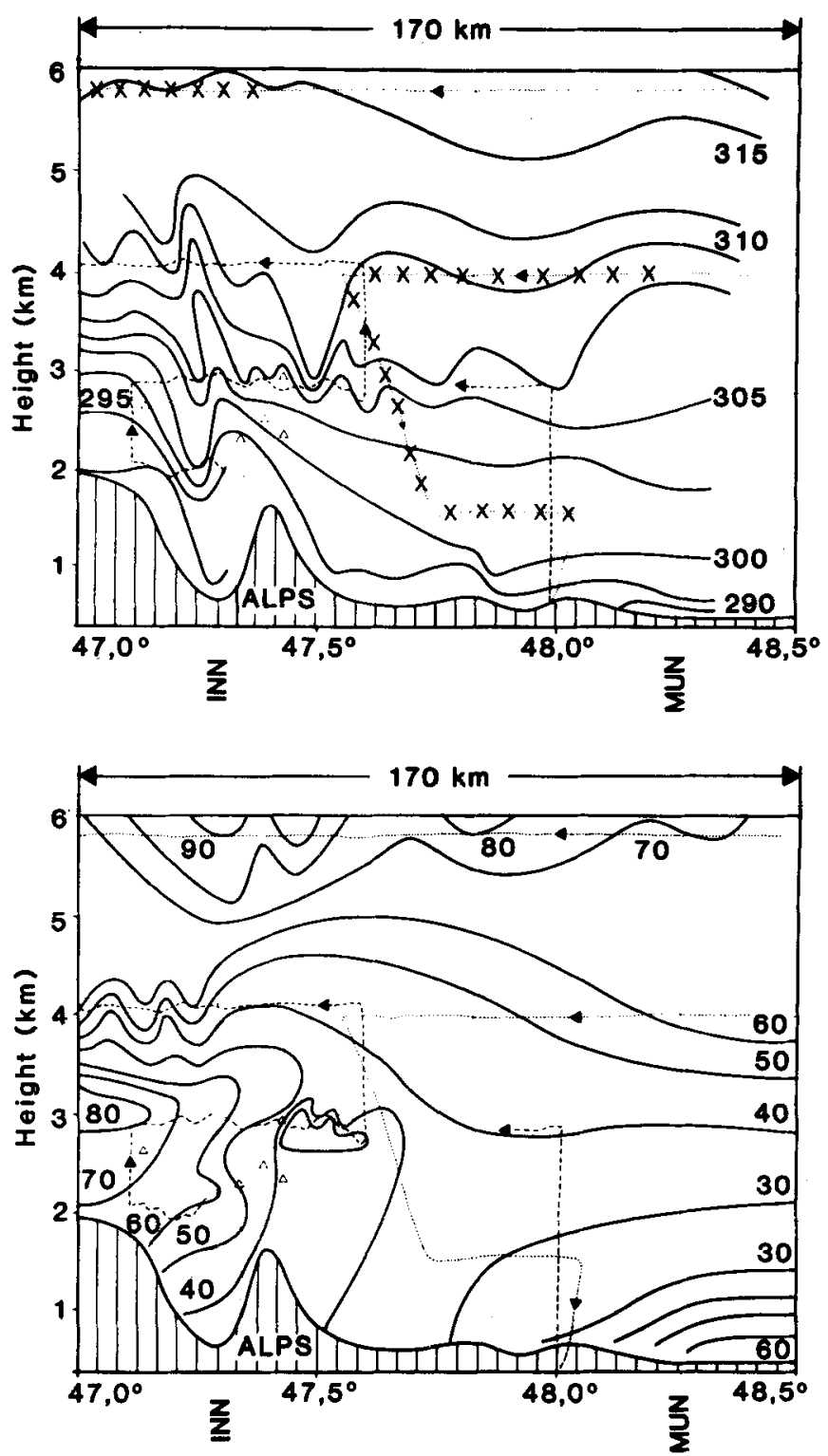

Figure 9. Cross-sections of potential temperatures in $\mathrm{K}$ (top) and relative humidity in \% (bottom) along a north-south line between BRE and MUN obtained from analysis of the Falcon, Queenair and motorized sailplane data on 8 November. The dashed lines indicate the flight legs.

Let us turn to a smaller scale. In Fig. 9, top, potential temperature for the mesoscale section from south on the left to north, from the Brenner-Pass (BRE) to Munich (MUN), is plotted. Above Innsbruck there is a wave of wavelength approximately $50 \mathrm{~km}$ with an amplitude of $1-2 \mathrm{~km}$. This wave is associated with small-scale lee waves. The isentropes above Innsbruck and the Inn valley show hydraulic jump behaviour. This is corroborated qualitatively by cloud observations from this area. 
At Munich at the same time a potential temperature of $286 \cdot 3 \mathrm{~K}$ was measured. This shows that Munich was located beneath an inversion and the foehn air was lifted above the block of cold air. Between the baseline of the Alps and some locations south of Munich the foehn had eroded the cold surface layer.

A wind velocity field cannot be presented because the aircraft involved in data gathering in this area were unable to measure wind components. However, dew-point measurements are available and the analysis is given in Fig. 9, bottom. A tongue of wet air above the Brenner Pass is drained down to Innsbruck. In the northern pre-alpine region, between $47.5^{\circ}$ and $48.0^{\circ}$, we find that the very dry foehn air has touched the ground confirming the potential temperature results mentioned above. North of this area, up to Munich a strong horizontal gradient of relative humidity close to the surface can be seen, which shows again that the foehn air has not reached the Munich area.

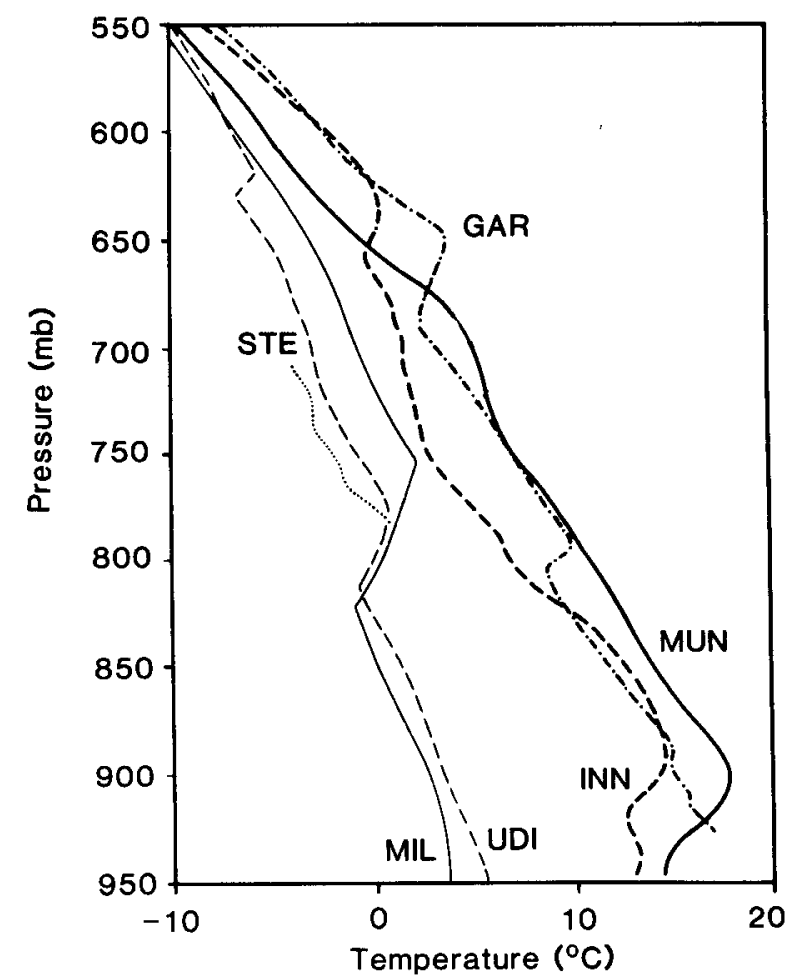

Figure 10. Vertical temperature profiles along the cross-section from northern Italy to southern Germany on 8 November.

The mesoscale differences in temperature for the lower troposphere are shown in Fig. 10. The temperature profiles above the upstream stations UDI and MIL, of the inner Alpine locations STE, INN, and the lee stations GAR and MUN are shown. We may distinguish three regions: below $800 \mathrm{mb}$; between 800 and $700 \mathrm{mb}$; and above. In the lower troposphere we find as expected temperature differences of $10^{\circ} \mathrm{C}$ between the windward and leeward side. At the leeward side the temperature at MUN is higher than those above the baseline of the Alps at GAR and the inner Alpine station INN. In the layer between 800 and $700 \mathrm{mb}$ low temperatures are observed at the windward side (MIL, UDI); the coldest area is above the main ridge at STE. Just $30 \mathrm{~km}$ north of STE, 
at INN, a temperature increase of $5^{\circ} \mathrm{C}$ is apparent. North of the barrier a further increase in temperature of $5^{\circ} \mathrm{C}$ was observed. Above the $700 \mathrm{mb}$ level temperature differences decrease with decreasing pressure.

\section{ON THE UPSTREAM CONDITIONS}

An essential question is: what are the basic-state properties of the atmosphere on the windward side during foehn? It is important to know which type of upstream stratification, wind shear and stability favour which type of lee circulation. With regard to the Alps it is a complicated problem to obtain upstream information. There are two rawinsonde stations south of the Alps: Milan and Udine. However, in the case of southerly flows the upstream atmosphere above MIL and UDI is influenced by the Appenine Mountains in Italy, between Genoa and Florence; these cause foehn effects on the northerly lee of the Appenine, visible even in satellite images.

In the case of south-westerly flows the vertical sounding at Udine might represent upstream characteristics for the flow over the eastern Alps. The location of Milan would be a better area for measuring upstream conditions for flow over the central Alps. However, with south-westerly flows the atmosphere above Milan is disturbed by the south-western edge of the Alps. So the upstream situation in the Alps is not as clear as it is in the case of airflow over the Rocky Mountains, where the sounding of Grand Junction represents a good approach of the windward side characteristics. One should bear these restrictions in mind when considering the soundings of Milan or Udine as 'undisturbed' upstream soundings.

In Fig. 4 we saw that a pool of cold air was present at the southern edge of the Alps. The mean temperatures between the surface and $5000 \mathrm{~m}$ evaluated from the vertical soundings are about $-1.0^{\circ} \mathrm{C}$ for this area. The air above Udine is very dry with a dew-point difference of $15^{\circ} \mathrm{C}$ in comparison to $3.0^{\circ} \mathrm{C}$ above Milan. In the layer between 800 and $600 \mathrm{mb}$ the dew-point differences are zero above Udine indicating that the south-westerly flow rises above the cold pool leading to cloud formation.

In Fig. 11 wind $(U)$, stability $(N)$ and wind direction $(\alpha)$ are given for the troposphere above Milan (left) and Udine (right). On the upstream side a stably stratified layer is located close to the surface, beneath $1 \mathrm{~km}$. In both cases the wind close to the surface comes from northerly directions. Above the stable layer the wind directions turn to south. This vertical wind structure indicates a recirculation beneath the basic southerly flow in the blocking region. One should bear in mind, however, that the realistic near-surface flow in this region appears to be more complicated than suggested by the available data.

Also evident in both stability profiles is the low-level inversion at mountain top level, indicating a layer of high thermal stability just above mountain top level (see Fig. 11). It is well known that this is a common feature in wave observation providing an ideal environment for waves. Similar low-level inversions were observed during the Boulder storm in 1972 as well as in England and Japan (Klemp and Lilly 1975). Across and below the stable layer there is a strong vertical wind shear of about $7 \mathrm{~m} \mathrm{~s}^{-1} \mathrm{~km}^{-1}$. During chinook storms a wind shear across the upstream low-level stable layer of about $6.4 \mathrm{~m} \mathrm{~s}^{-1} \mathrm{~km}^{-1}$ was reported (Brinkmann 1973).

Klemp and Lilly (1975) have shown that an atmospheric vertical profile containing a layer of high thermal stability plus a tropospheric temperature and wind speed profile where the distance from the mountain top to the tropopause is approximately half the vertical wavelength, $2 \pi U / N$, of a stationary hydrostatic wave, produces maximum wave and surface wind amplitude. In the present foehn case a mean stability of $0 \cdot 012 \mathrm{~s}^{-1}$ and 

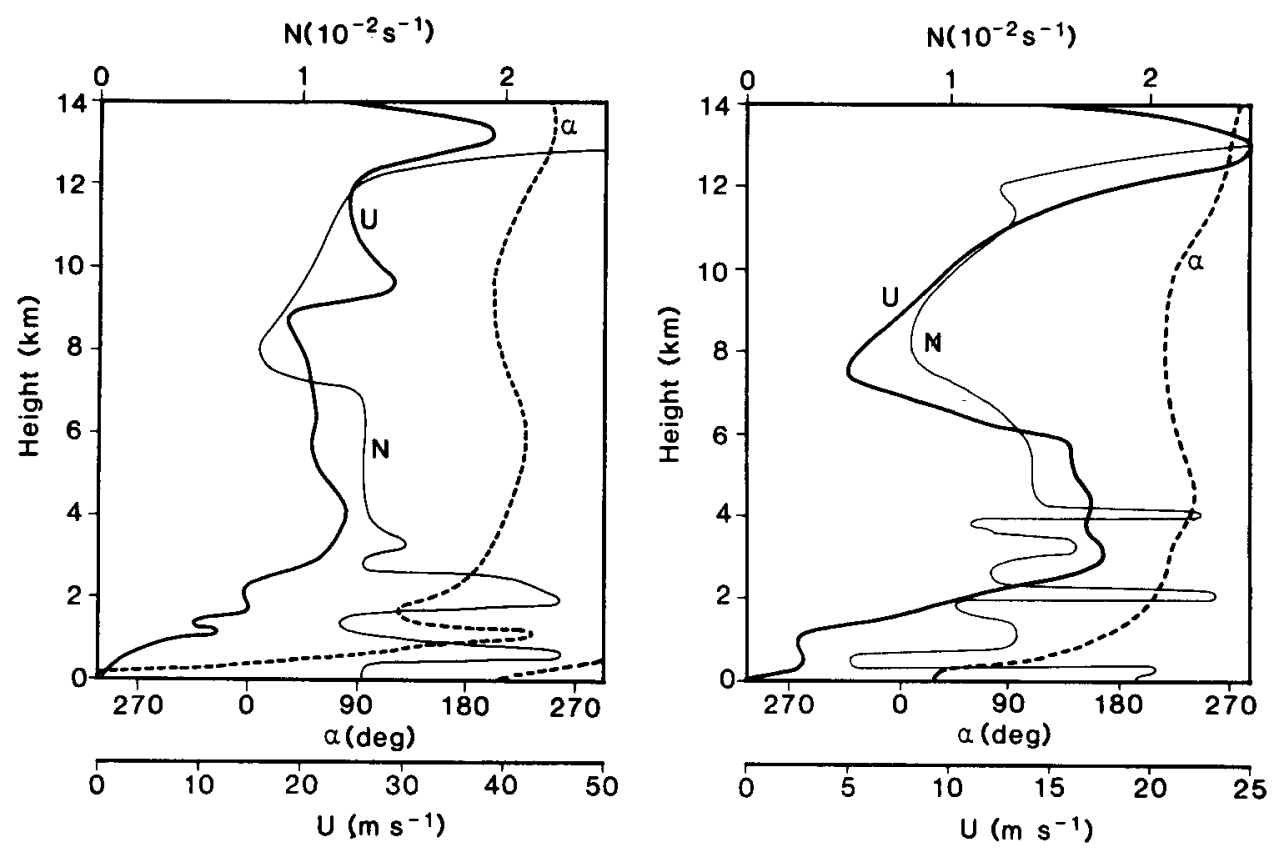

Figure 11. Vertical profiles of wind speed $U$, wind direction $\alpha$ and Brunt-Väisälä frequency $N$ as functions of height for Milan (left) and Udine (right) on 8 November $198212 \mathrm{GMT}$.

a mean wind of $8 \mathrm{~m} \mathrm{~s}^{-1}$ perpendicular to the Alps can be estimated from Fig. 11. We come to a vertical wavelength of $4.2 \mathrm{~km}$. This explains to some extent why a strong wave amplitude was not associated with the foehn on 8 November. We can see that the atmosphere was not 'tuned' for large amplitude wave response on that day.

The streamline fields are strongly influenced by changes in the wind profile above the possible region of strongest steepening of the wave (Peltier and Clark 1979) which is $3 / 4$ the wavelength. Peltier and Clark point out that the stronger the wind shear above the region of steepening the stronger the steepening. In the present case the wind is almost constant with height above this level. Both features explain why the present foehn was not associated with a large amplitude mountain wave. The question why surface gusts of an unusual type nevertheless occurred remains. It seems clear that the strong surface gusts are not associated with a strong wave amplitude above. These considerations are confirmed by numerical simulations of chinook events by Klemp and Lilly (1978) and Peltier and Clark (1979). Hydrostatic simulations of chinooks have yielded a hydrostatic mountain wave with an amplitude of $3.5 \mathrm{~km}$ with surface winds up to $55 \mathrm{~m} \mathrm{~s}^{-1}$. Non-hydrostatic simulations show for the same event amplitudes up to $7 \mathrm{~km}$ (as observed) and gusts up to $58 \mathrm{~m} \mathrm{~s}^{-1}$.

The structure of the mesoscale wave suggests that some wave breaking has occurred in the layer between 3 and $5 \mathrm{~km}$. Linear theory is able to predict where this mountain-forced wave breaking occurs aloft. Following Peltier and Clark one can estimate the critical height $z_{\mathfrak{c}}$, where the wave overturns, using the upstream wind and temperature profiles

$$
\int_{0}^{z_{\mathrm{c}}}(N / U) d z=3 \pi / 2
$$


with $N$ the Brunt-Väisälä frequency and $U$ the mean velocity in the layer $d z$. In our case the rawinsonde observations at Milan might be characteristic for the upstream flow structure. The critical height of wave breaking is evaluated to be $4.2 \mathrm{~km}$ using the observations of Milan which are corroborated by the analysis shown in Fig. 9, top.

Manins and Sawford (1982) and others have pointed out that the occurrence of blocking is controlled by a Froude number, $F=U(g h \Delta \theta / \theta)^{-1 / 2}$, where $U$ is the upstream ambient wind speed, $\theta$ a representative potential temperature and $\Delta \theta$ the change in potential temperature from near the surface to above the ridge height $(h)$ upwind of the ridge. Their observations suggest that below Froude number 1.6 blocking occurs. In the present case we find Froude numbers of 0.35 (for an orography height of $2000 \mathrm{~m}$ ). The magnitude of these Froude numbers confirms the possibility of the occurrence of blocking south of the Alps. Of practical importance is the height below which we find reversed flow and above which the flow crosses the barrier. Hunt and Snyder (1980) and Baines (1979) derived an equation to estimate the height $z_{\mathrm{s}}$ of this splitting point for low Froude number flows: $z_{\mathrm{s}}=h(1-2 F)$. For the present event this height is estimated to be $600 \mathrm{~m}$. From Fig. 11 similar heights have been deduced for the upstream atmosphere. The above mentioned blocking conditions seem physically reasonable for the present event but contain no information as to what form the blocking will take or other features.

The soundings above Munich and Milan have shown that the tropopause above Munich (Milan) was at about $168(190) \mathrm{mb}$. It is characteristic of foehn events that the tropopause is lower on the windward side than on the leeward side (Hoinka 1980). In the present case the difference in height is about $800 \mathrm{~m}$.

\section{THE MOMENTUM FLUX}

One of the most important quantitative measures of mountain wave intensity is the exchange of momentum between the atmosphere and the sloping lower boundary. The vertical flux of horizontal momentum is evaluated by computing the eddy momentum flux integral, where primes represent deviations from the horizontal flight leg average:

$$
M=L^{-1} \int_{0}^{L} \rho u^{\prime} w^{\prime} d x
$$

with $L$, the length of the flight leg, $=300 \mathrm{~km}$. The mean and additionally the trends are removed by least-square fitting. Wind speeds were only measured by the Falcon, thus momentum fluxes were evaluated only above $5 \mathrm{~km}$.

In Fig. 12 the vertical fluxes of meridional (crosses), latitudinal (circles) momentum and a combination of both (triangles) are given. In the troposphere at all levels the fluxes are negative, as would be expected from mountain wave theory. The magnitude of the flux of westerly momentum results close to $0 \cdot 1 \mathrm{~Pa}$, that of southerly is between 0.1 and $0.3 \mathrm{~Pa}$ and that evaluated using the wind speed is between 0.2 and $0.3 \mathrm{~Pa}$. The differences corroborate that the main flow comes from south-west. Profiles similar in magnitude were obtained during the WAMFLEX experiment, published recently by Lilly and co-workers (1982).

As we have seen, the flow pattern was different beneath $5 \mathrm{~km}$. The momentum flux profiles shown in Fig. 12 cannot represent, therefore, what occurred in the lower layers. Due to lack of aircraft data a rough estimate will be made by evaluating the linear mountain drag according to Miles and Huppert (1969):

$$
M=\pi \rho U N h^{2} /(4 L) \text {. }
$$




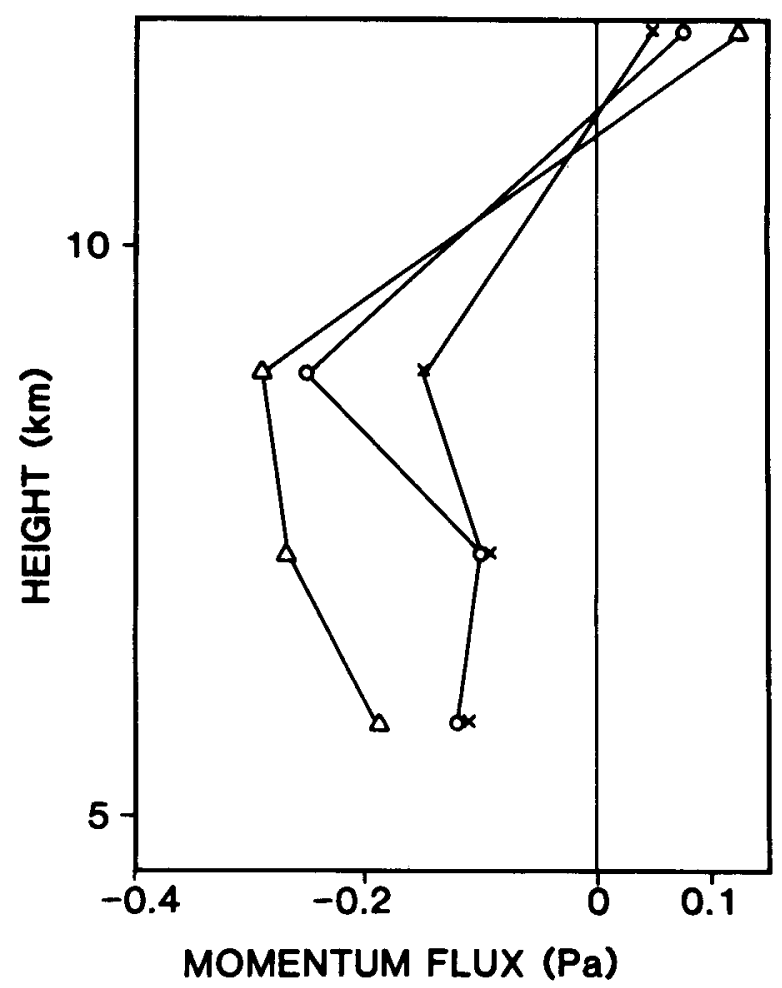

Figure 12. Measured profiles of wave momentum flux averaged over $300 \mathrm{~km}$ along a north-south profile across the Alps on 8 November. The latitudinal (meridional) fluxes are indicated by circles (crosses). The flux values evaluated using the wind speed are given by triangles.

Using $h=2000 \mathrm{~m}, N=0 \cdot 01 \mathrm{~s}^{-1}, U=10 \mathrm{~m} \mathrm{~s}^{-1}$ and $L=300 \mathrm{~km}$ the linear mountain drag turns out to be approximately $1.6 \mathrm{~Pa}$, which is considerably more than the amount evaluated for the mid troposphere. A further rough estimate is to compute the vertical integral of the pressure difference $d p$ across a mountain range of height $h$

$$
D=L^{-1} \int_{0}^{h}(d p) d z
$$

With a pressure difference of about $20 \mathrm{mb}$ and assuming that $d p$ decreases in a linear way according to height, to the top of the Alps, the pressure force is about $6.7 \mathrm{~Pa}$. The surface drag of the wind on roughness elements should be added to the cross-mountain pressure force. We estimate the direct wind drag to be about $0.5 \mathrm{~Pa}$, based on a r.m.s. surface velocity of $10 \mathrm{~m} \mathrm{~s}^{-1}$ over $30 \mathrm{~km}$ of the lee slope and a drag coefficient, $C_{\mathrm{D}}$, of 0:01 $\left(D=C_{\mathrm{D}} u^{2} \rho / 2\right)$. It appears that this term is significantly smaller than the pressure drag, though uncertainties in both are rather large.

As we have seen there is a large difference between the surface drag and the mid-tropospheric wave momentum flux. This is similar to numerical results shown by Peltier and Clark (1983) for small Froude number flows over idealized terrain, in which large low-level gradients of momentum flux were observed in convectively overturning waves. The wave structure shown in Fig. 9 suggests that overturning has occurred. A possible process leading to rapid decrease in momentum flux according to height was suggested by D. Lilly: the convective overturning produces an upward heat flux which 
increases the stratification and thereby reduces pressure downstream of the overturning region. This reduced pressure is then sufficient to balance the wave momentum flux divergence with little or no change in the downstream velocity profile.

TABLE 1. COMPARISON OF DRAG VALUES

\begin{tabular}{lcc}
\hline & $\begin{array}{c}\text { Drag } \\
(\mathrm{Pa})\end{array}$ & $\begin{array}{c}\text { Domain size } \\
(\mathrm{km})\end{array}$ \\
\hline $\begin{array}{l}\text { Boulder storm case } \\
\text { 11 January 1972 }\end{array}$ & 4.7 & 200 \\
Airflow over the & & \\
Rocky Mountains & $0 \cdot 6$ & \\
$\quad$ 17 February 1970 & & \\
ALPEX Pyrenees & 0.4 & 300 \\
23 March 1982 & & \\
Foehn 8 November 1982 & & 300 \\
$\quad$ Momentum flux & $0 \cdot 3$ & 300 \\
$\quad$ Linear mountain drag & 1.6 & 300 \\
$\quad \begin{array}{l}\text { Pressure drag } \\
\text { Surface drag }\end{array}$ & $6 \cdot 7$ & 30 \\
Appalachian Mountains & $0 \cdot 5$ & 5 \\
$\quad$ Mountain drag & & 4000 \\
Drag exerted & $5 \cdot 0$ & 300 \\
$\quad$ by cyclones & 0.5 & \\
Frictional drag & & \\
\hline
\end{tabular}

Finally, a comparison of momentum flux values is given in Table 1 to show the importance of the present foehn case. During the Boulder storm on 11 January 1972 (Klemp and Lilly 1978) a drag of $4.7 \mathrm{~Pa}$ was evaluated for the layer between 7 and $9 \mathrm{~km}$. For a flow over the Colorado Rockies on 17 February 1970 (Lilly and Kennedy 1973) a drag of $0.6 \mathrm{~Pa}$ was computed. Recently, during ALPEX, 0.4 Pa was evaluated for a flow over the Pyrenees (Hoinka 1984). For small rolling hills Smith (1978) has obtained a magnitude of $5.0 \mathrm{~Pa}$ for the mountain drag. Synoptic-scale cyclones have substantial large drags of $0.5 \mathrm{~Pa}$ (Pfeffer 1967). A further component of the drag exerted between the earth and the atmosphere is the frictional drag. The relative importance of this drag is illustrated by its magnitude of $0 \cdot 2 \mathrm{~Pa}$.

\section{ENERGY AND DISSIPATION IN TURBULENCE}

In this section we present an examination of the dissipation rates using rawinsonde observation combined with aircraft data. It has been shown by Lilly and Kennedy (1973) that in the case of steady-state, two-dimensionality and with the aid of the hydrostatic approximation, the viscous dissipation of energy along a streamline is given by

$$
\varepsilon=-U \partial\left(\Phi+u^{2} / 2\right) / \partial x
$$

with $\Phi$, the Montgomery function, $=c_{p} T+g z$. Thus, the decrease of the magnitude of the term in brackets along an isentrope is a good measure of the rate of kinetic energy dissipation. 
There are two ways of determining the Montgomery potential: integrate upwards from a surface station using balloon or aircraft sounding; integrate from a level without dissipation (Lilly and Kennedy 1973). As we have seen the orientation of the jet across the Alps was approximately parallel to a line Milan-Munich. Therefore, both locations are approximately on the same trajectory, allowing determination of the loss of energy due to dissipation using the soundings of Milan and Munich.

First we constructed combined vertical soundings for the upstream location, Milan, and the northern lee location, Munich, using rawinsonde and aircraft data. Following Lilly and Kennedy our method was then to assume that the quantity in brackets was constant along $\theta=328 \mathrm{~K}$, which was the case considering the values obtained from the soundings above the windward and leeward side. The measured kinetic energy was subtracted from it to obtain an upper boundary condition for $\Phi$. The hydrostatic equation was then integrated downward using the analysed pressure levels of the isentropes to obtain a field of $\Phi$, to which the measured kinetic energy was added.

TABLE 2. AVERAGE DISSIPATION RATES ESTIMATED FROM ENERGY LOSS ALONG ISENTROPES

\begin{tabular}{lccccc}
\hline & \multicolumn{5}{c}{ Dissipation rates } \\
\cline { 2 - 5 } & \multicolumn{5}{c}{$\frac{1}{2} U^{2}+\Phi$} \\
$\theta$ & $\begin{array}{c}\text { Milan } \\
(\mathrm{K})\end{array}$ & $\begin{array}{c}\text { Munich } \\
\left(\mathrm{m}^{2} \mathrm{~s}^{-2}\right)\end{array}$ & $\begin{array}{c}\text { Difference } \\
\left(\mathrm{m}^{2} \mathrm{~s}^{-2}\right)\end{array}$ & $U$ & $\varepsilon$ \\
\hline 325 & -2406 & -2535 & -126 & 16 & 67 \\
320 & -6481 & -6557 & -76 & 10 & 26 \\
315 & -10686 & -10858 & -172 & 13 & 72 \\
310 & -15052 & -15323 & -271 & 14 & 126 \\
305 & -19591 & -20004 & -413 & 12 & 167 \\
300 & -24221 & -24966 & -745 & 12 & 308 \\
295 & -28933 & -29865 & -932 & 7 & 218 \\
\hline
\end{tabular}

In Table 2 the values of $\Phi$ for the southern and northern parts are shown for various isentropes. Utilizing the average wind for each layer, shown in the fifth column, we then compute the estimates for the dissipation averaged over the $300 \mathrm{~km}$ of each isentrope. The estimates are shown in the last column. Above the $315 \mathrm{~K}$ level for the upper troposphere the dissipation rates are approximately $50 \mathrm{~cm}^{2} \mathrm{~s}^{-3}$. A dissipation rate of about $150 \mathrm{~cm}^{2} \mathrm{~s}^{-3}$ can be seen for the mid troposphere.

An independent check of these dissipation rates can be made by taking the largescale energy budget into consideration. From the equation of motion the removal of energy by dissipation can be expressed as

$$
\varepsilon=U \partial\left(\int \rho u^{\prime} w^{\prime} d x\right) / \partial z
$$

with $U$ the mean horizontal velocity of the corresponding layer. Above the $315 \mathrm{~K}$ level a dissipation rate of $50 \mathrm{~cm}^{2} \mathrm{~s}^{-3}$ leads to an increase of the momentum flux from zero to $0.3 \mathrm{~Pa}$ in a depth of $2 \mathrm{~km}$ at a height of $10 \mathrm{~km}$. This corresponds well with the magnitude of the momentum flux obtained from aircraft data, shown in Fig. 12. A dissipation rate 
of $200 \mathrm{~cm}^{2} \mathrm{~s}^{-3}$ taken from Table 2 leads to a further increase of the momentum flux from 0.2 to $1.6 \mathrm{~Pa}$ at a depth of $70 \mathrm{mb}$ at an approximate height of between 5 and $6 \mathrm{~km}$. This measurement is more or less in accord with linear estimates.

However, a rough error analysis suggests that with a stability in the aircraft instrumentation of $0.2 \mathrm{~K}$ in temperature and of $0.25 \mathrm{mb}$ in pressure along a horizontal run, an error in the Montgomery potential of about $100 \mathrm{~m}^{2} \mathrm{~s}^{-3}$ can be expected; a similar error level is obtained for the rawinsonde data. With a horizontal velocity of $13 \mathrm{~m} \mathrm{~s}^{-1}$ an error level of $45 \mathrm{~cm}^{2} \mathrm{~s}^{-3}$ is evaluated. Values below this should be taken to be scatter introduced by instrumental errors and other uncertainties. The momentum flux value obtained for the upper atmosphere is close to this error level and therefore questionable, but, on the other hand, is confirmed by direct measurements.

\section{ON THE STATIONARITY}

Lilly (1978) reported oscillations of the principal wave trough and surface pressure of about 4 to 5 hours during the Boulder windstorm. Very recently, Clark and Farley (1984) reported that in their numerical simulations non-stationary behaviour of the streamlines was observed in the core of the main wave. The simulated flow gives the appearance of repeatedly building up regions of convective instability with subsequent breaking down of these instabilities through convective motions. This cycle produces an apparent oscillation of the lee edge of the vertically steep isentropes causing them to appear to move back and forth in the main flow direction with a period of approximately 10 to 20 minutes. This period is the same as that between large surface gusts. Observers in gliders also report that small-scale waves shift back and forth above Innsbruck in this area. This would confirm to some extent the results of the numerical simulations of Clark and Farley.

The data used to sketch the cross-sections (Figs. 8 and 9) seem to fit very well. However, those involved in analysing aircraft data know that this is not always the case. So, in Fig. 13(a) the time dependence of data is shown along a $50 \mathrm{~km}$ track back and forth at an altitude of $4 \mathrm{~km}$, where the Queenair flew from the Karwendel mountain (KAR) to the Brenner Pass (BRE) and back at the same height. Within the short delay of 18 min between starting and returning to the starting point the main patterns are reproduced reasonably well. The question remains how far this is proof of stationarity of the event. One possible feature could be that the entire structure has been advected downstream or back.

The location of the tracks flown by the Queenair and plotted in Fig. 13(a) is directly in the main core of strong waves above the Inn valley and is favourable for the occurrence of processes reported by Clark and Farley. However, the delay of $18 \mathrm{~min}$ between the two Queenair flights is within the magnitude of the characteristic period. The speed of the aircraft is too low to get information on the characteristic period of 10 to $20 \mathrm{~min}$.

From Fig. 9, top, strong small-scale wave activity is apparent at a height of $3 \mathrm{~km}$ between Innsbruck and $47.5^{\circ} \mathrm{N}$. The Queenair took data along this track twice, with a delay of one hour. The temporal evolution of the potential temperature is given in Fig. 13(b). The potential temperature structure has apparently changed along the flight track above INN and KOC after one hour. The amplitudes have increased indicating that small-scale features were unsteady in this area. Satellite observations of lee wave clouds frequently show considerable variations in the phase and the amplitude of the wave crests in the direction perpendicular to the mean wind. Some of the apparent differences between the data from reciprocal runs may therefore be due to quite small differences in the cross-wind position of the flight tracks. 
(a)

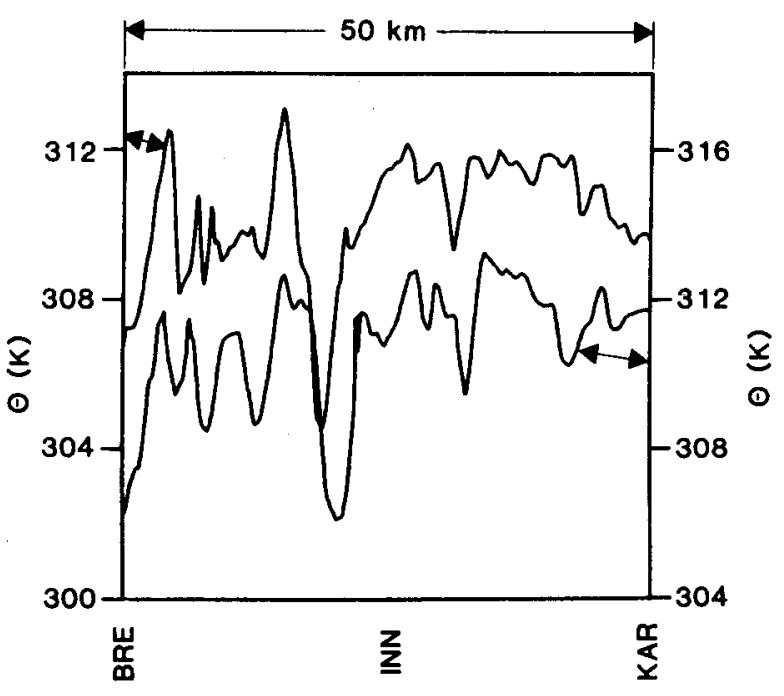

(b)

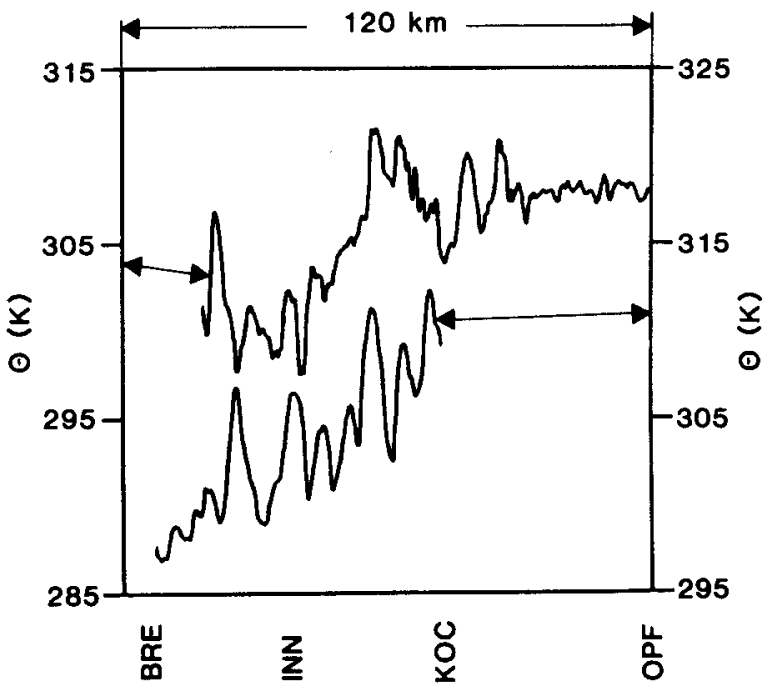

Figure 13. The top figure shows the potential temperature between BRE and KAR as measured by the Queenair at a height of $4 \mathrm{~km}$. The bottom figure shows the potential temperature between INN and OPF as measured by the Queenair at a height of $3 \mathrm{~km}$. The left-hand (right-hand) side scaling is for the upper (lower) track, as indicated by arrows.

In the analysis (Figs. 8,9) it is assumed that the flow is two-dimensional and quasi-steady. Neither assumption could be tested rigorously with the available data; however, the fact that aircraft traverses were repeated suggests that the dominant features close to the mountain, once established, are usually fairly steady over time scales of $3 \mathrm{~h}$, which are similar to those observed during WAMFLEX. In conclusion, we can see that the event was approximately stationary in the mesoscale but with some small-scale non-stationary developments.

\section{THE OBSERVATION OF TURBULENCE}

In this section some comments on turbulence on the lee side in the troposphere will be briefly summarized. Mountain lee waves are frequently accompanied by a low-level 
turbulence zone in the lee $(2-5 \mathrm{~km}$ height). This highly turbulent region of nearly neutral stability is found immediately to the lee of the mountain between the ground and an upper stable layer in which the wave motion occurs. In Fig. 14 the vertical structure of stability, given by the Brunt-Väisälä frequency, is plotted for the lee side atmosphere above MUN, GAR and $\mathrm{HOH}$. In all cases we can see the stable layer between 4 and $5 \mathrm{~km}$ and a less stable layer below. The profile $\mathrm{HOH}$ seems to be almost out of phase with MUN and GAR. This is due to the fact that the rawinsonde was launched at $06 \mathrm{GMT}$ in the morning while the other observations at MUN and GAR were made at noon. Additionally only above GAR can we see a second low-level stable layer at $3 \mathrm{~km}$. GAR is located at the foothills of the Alps in the shadow of the high mountain step. This low-level stability peak suggests that close to the northern edge of the Alps beneath the mean height no turbulence could have occurred and the foehn has not reached the ground in the immediate lee at GAR. This is confirmed by local observers.

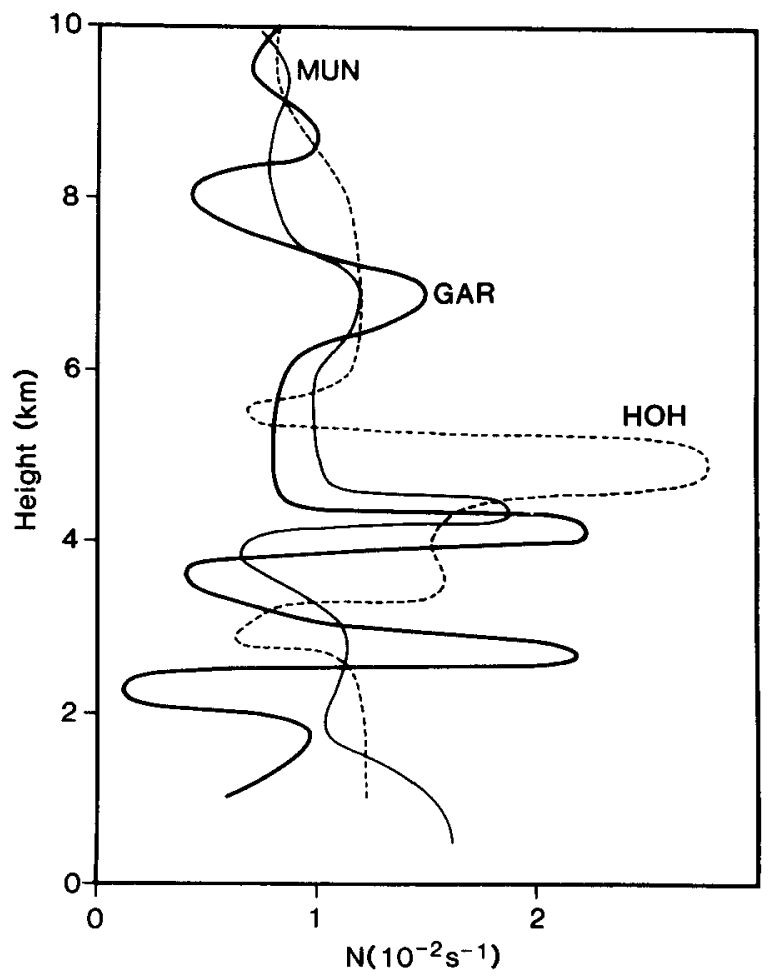

Figure 14. Vertical profiles of the Brunt-Väisälä frequency $N$ as a function of height for the lee side stations GAR, HOH and MUN.

Similar observations above the Rocky Mountains have confirmed the appearance of elevated low-level turbulence in the immediate lee of the mountain (Lilly 1978). In our case we have chosen the lee side area between $47.5^{\circ}$ and $48.0^{\circ} \mathrm{N}$. For this region we have additional low-level measurements at 4 and $1.6 \mathrm{~km}$ above m.s.l. gathered by the Falcon.

In the case of light to severe turbulence we should expect apparent fluctuations in all three velocity components. This is not the case at all levels above $5 \mathrm{~km}$, where 
fluctuations were encountered only for the vertical component. However, for the $4 \mathrm{~km}$ (Fig. 15(a), (b), (c)) and the $1.6 \mathrm{~km}$ (not shown) levels in the northern lee all three wind components fluctuate apparently with maximum deviations of $5 \mathrm{~m} \mathrm{~s}^{-1}$ in the horizontal and $2 \mathrm{~m} \mathrm{~s}^{-1}$ in the vertical components. Additionally, the turbulence behaviour can be seen in Fig. 15(d), which shows the record of aircraft vertical acceleration from the inertial platform, for the turbulent interval. The magnitude of acceleration is in the range of $0 \cdot 2 \mathrm{~g}$, which means light to moderate turbulence. Lilly (1978) reported for a severe turbulence event horizontal wind variations of $10-20 \mathrm{~m} \mathrm{~s}^{-1}, 10 \mathrm{~m} \mathrm{~s}^{-1}$ in the vertical component and fluctuations in acceleration up to $0.5 \mathrm{~g}$.
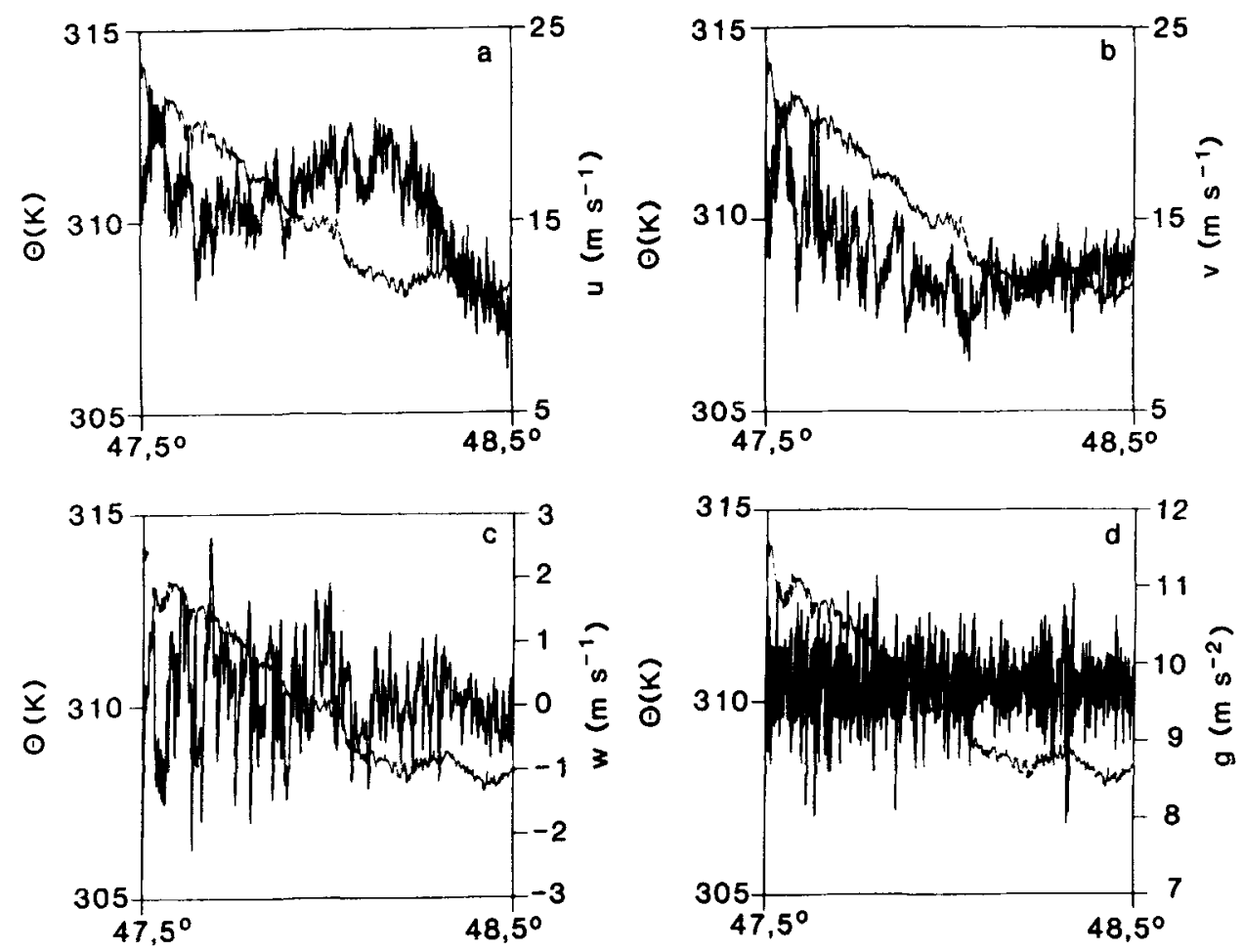

Figure 15. Wind $u(\mathrm{a}), v(\mathrm{~b})$ and $w$ (c) at a height of $4 \mathrm{~km}$ in the northern lee of the Alps measured by the Falcon. The vertical aircraft acceleration is given in (d).

In Fig. 16 vertical profiles of the least-square distribution of the three components of wind and aircraft acceleration are given for the lee side troposphere. The values shown are obtained from the corresponding power spectra. Perturbations with wavelength $>10 \mathrm{~km}$ were eliminated by filtering. It appears that above $6 \mathrm{~km}$ all variances are minor and in the lower levels all the variances are major. This indicates that the relatively strongest turbulence occurred at a height of $4 \mathrm{~km}$. Subjective pilot reports of turbulence were found to be correlated with $V A=\overline{\left(u^{\prime 2}\right)^{1 / 2}}$ values as follows: $0.7<V A<1.0 \mathrm{~m} \mathrm{~s}^{-1}$, light; $1.0<V A$, moderate. Severe turbulence was not observed. These classifications apply only to the present work since they are dependent on the characteristics of the 


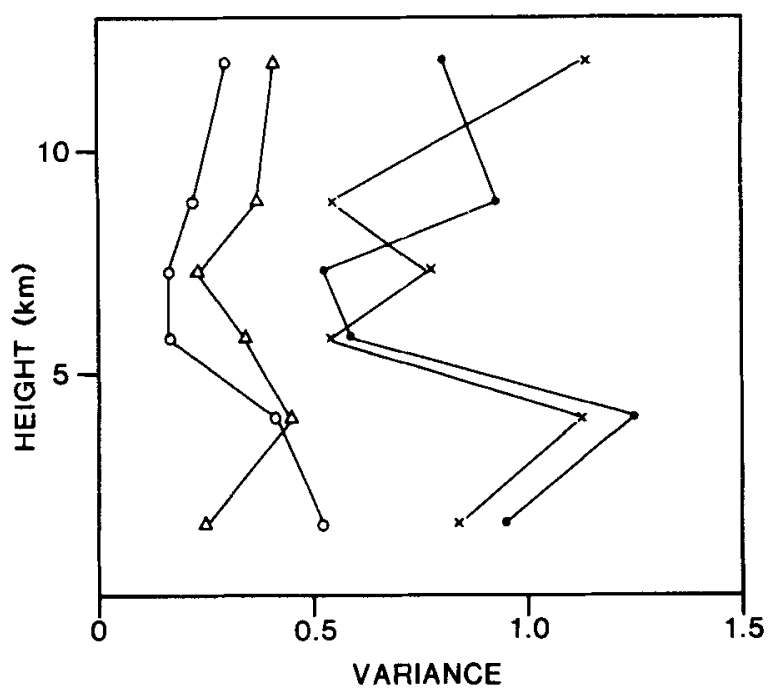

Figure 16. The variances of $u$ (dots), $v$ (crosses), $w$ (triangles) and of the acceleration (circles) as functions of height. The velocity variances are given in $\mathrm{ms}^{-1}$ and that of the acceleration in $\mathrm{m} \mathrm{s}^{-2}$.

aircraft. For comparison, the relations reported from Lester and Fingerhut (1974) are given: $0.4<V A<0.9$, light $0.9<V A<1.5$, moderate; $1.5<V A$, severe. These values are characteristic of the NCAR aircraft Queenair. These relations correspond approximately to those obtained for the Falcon.

There is some evidence that turbulence at low levels is related to the turbulence occurring close to the surface. So in the following we look at the surface turbulence state. In most cases the foehn does not extend very far into the flat terrain in southern Bavaria. This feature is highlighted in Fig. 17, where surface wind observations are shown for INN, $\mathrm{HOH}$ and MUN. Time runs from right to left. We can see strong gustiness with gusts up to $25 \mathrm{~m} \mathrm{~s}^{-1}$ at INN. At $\mathrm{HOH}$ at a distance of $40 \mathrm{~km}$ from the baseline of the Alps gusts up to $14 \mathrm{~m} \mathrm{~s}^{-1}$ were observed. At MUN at a distance of $80 \mathrm{~km}$ from the baseline we do not see any gusts, merely slight increases of wind speed up to $5 \mathrm{~m} \mathrm{~s}^{-1}$. For all stations the wind direction is close to $180^{\circ}$ with limited but strong to light variances in the direction. Lilly et al. (1982) have correlated observed momentum flux with maximum surface wind gusts for WAMFLEX. For gusts between 20 and $30 \mathrm{~m} \mathrm{~s}^{-1}$, as observed at Innsbruck during the present foehn case, they obtained momentum flux values between 0.3 and $0.4 \mathrm{~Pa}$, which is in good agreement with our result presented in section 6 .

\section{SUMMARY}

The foehn on 8 November 1982 was one substantially strong event of the last decade. This foehn was linked with strong mountain waves below an altitude of $6 \mathrm{~km}$ at Innsbruck. These mountain waves were convectively overturned. Above the region of overturning only a mesoscale double mountain wave with an amplitude of $1 \mathrm{~km}$ was observed. On the near-surface upstream side there was a blocking of cold air in northern Italy, which is usually observed during foehn. The peak gusts observed on the lee side of the Alps were compatible with the observed wave amplitude and momentum flux. 

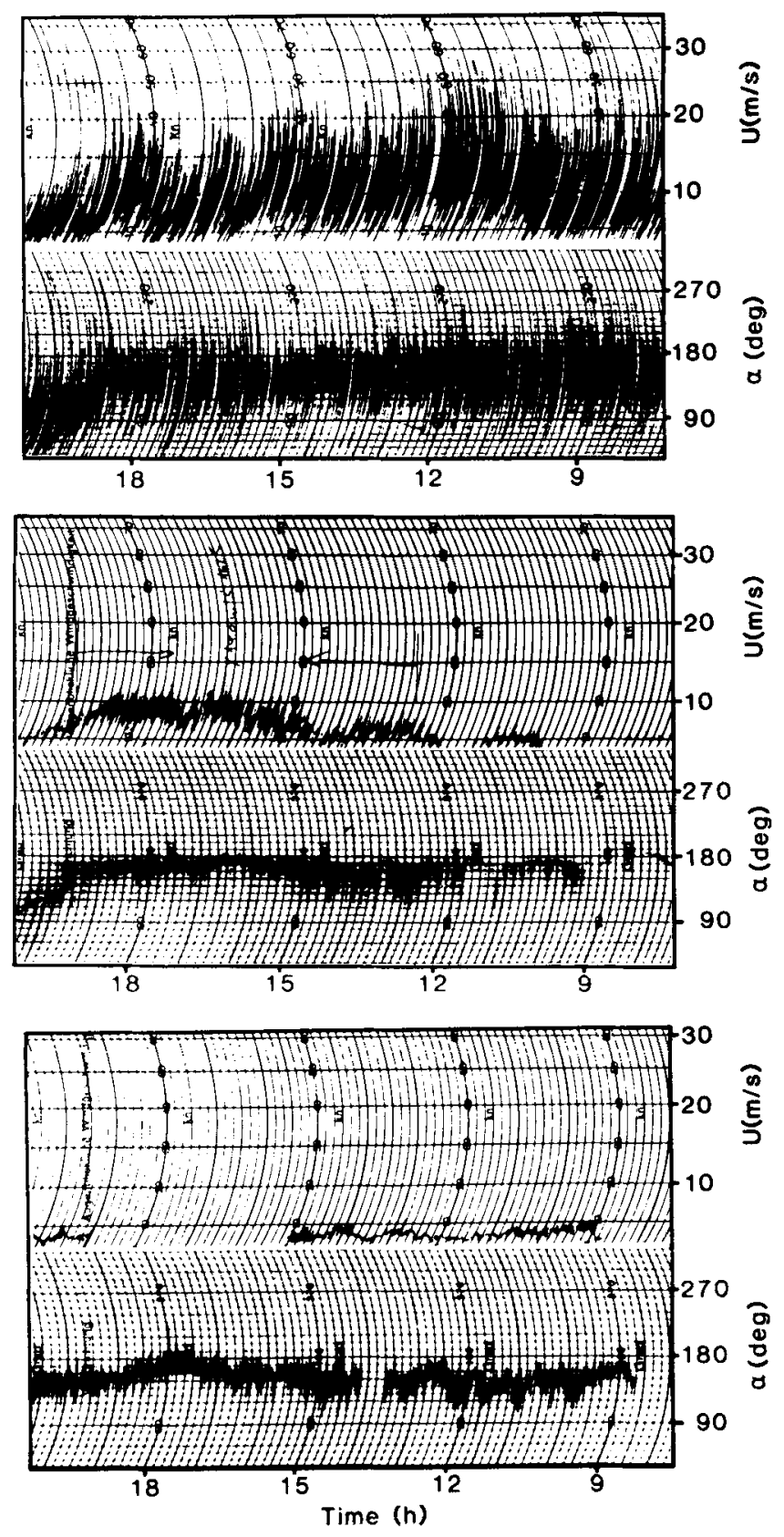

Figure 17. The wind velocity and direction as a function of time at INN (top), HOH (mid) and MUN (bottom) on 8 November. Note that time runs from right to left. (Courtesy of R. Steinacker, W. Attmannspacher and D. Marzoch.) 
In the present case airflow across the Alps was found to be characterized by a well-defined stable layer located at about mountain top level in the upstream flow. This agrees with observations of the upstream atmosphere during chinook. Strong vertical wind shear across and below this can be found in both cases. During foehn and chinook maximum surface gusts are stronger than the mean wind speed at any level in the troposphere upstream. In the case of airflow over the Rocky Mountains the troposphere is modified above the barrier leading to a less stable stratification on the lee side. A similar lee side destabilization of the troposphere was observed in the foehn case described here.

Most of the results are confirmatory in relation to those obtained for the airflow over the Rocky Mountains. However, this paper shows one difference from the published results of mountain wave events over the Rocky Mountains, namely the large difference between the surface drag and the mid-tropospheric wave momentum flux. The magnitude of the observed momentum flux above $6 \mathrm{~km}$ is about $0.3 \mathrm{~Pa}$. Energy budget calculations show substantially larger momentum exchange due to dissipation below $6 \mathrm{~km}$ up to $1.4 \mathrm{~Pa}$. The surface drag was estimated to be $6.7 \mathrm{~Pa}$ based on the near-surface pressure gradients across the Alps of $10 \mathrm{mb}$ per $100 \mathrm{~km}$. The reason for the large low-level gradient of momentum flux might be that the upward heat flux produced by the convective overturning increases the stratification and thereby reduces pressure downstream of the overturning region. This reduced pressure would appear to be sufficient to balance the wave momentum flux divergence with little or no change in the downstream velocity profile.

The observed atmospheric patterns above the Alps presented here confirm that it was important and necessary to make measurements as described. Due to the fact that only a relatively small number of well-defined cases of airflow over mountains has been obtained, additional examples are needed in order to determine the representativeness of the existing data.

\section{ACKNOWLEDGMENTS}

The list of contributors to the work reported here is long. M. E. Reinhardt initiated the plan for performing the experiment. The scientific observers on board the aircraft were: H. Fimpel (Falcon), W. Peters (Queenair), H. Willeke (motorized sailplanes). The data processing was carried out by H. Fimpel, W. Peters and H. Willeke. F. Adler and W. Dietrich made surface measurements along the baseline between Munich and the Alps. D. Marzoch from the German Weather Service (DWD) at Munich is to be thanked for forecast support during the experiments. W. Attmanspacher from the DWD at Hohenpeissenberg is to be thanked for providing rawinsonde data. R. Sladkovics from the Fraunhofer Society in Garmisch performed the rawinsonde observation at Garmisch. P. Seibert and R. Steinacker of the University of Innsbruck were very helpful with their knowledge and advice for the prediction of the weather event. They also launched a rawinsonde in the Inn valley. G. Jacob is to be thanked for the excellent job of preparing the drawings.

\author{
Baines, P. G. \\ Brinkmann, W. A. R.
}

\section{REFERENCES}

1979

1973
Observations of stratified flow past a three-dimensional barrier. J. Geophys. Res., 84, 7834-7838

'A climatological study of strong downslope winds in the Boulder area'. NCAR Cooperative Thesis No. 27, University of Colorado 
Brinkmann, W. A. R.

Clark, T. L. and Farley, R. D.

Durran, D. R. and Klemp, J. B.

Hauf, Th.

Hoinka, K. P.

Hunt, C. R. and Snyder, W. H.

Kennedy, P. J

Klemp, J. B. and Lilly, D. K.

Lester, P. F. and Fingerhut, W. A.

Lilly, D.

\section{Lilly, D. K. et al.}

Lilly, D. and Kennedy, P. J.

Manins, P. C. and Sawford, B. L.

Miles, J. W. and Huppert, H. E.

Peltier, W. R. and Clark, T. L.

Pfeffer, R. L.

Smith, R.

Smith, R. et al.
1982

1980

1984

1974

1984

1980

1982

1975

1978

1974

1972

1978

1982

1973

1982

1969

1979

1983

1967

1978

1982
Strong downslope winds at Boulder. Mon. Wea. Rev.. 102, 592-602

Severe downslope windstorm calculations in two and three dimensions using anelastic, interactive grid nesting: a possible mechanism for gustiness. J. Atmos. Sci., 41, 329-350

The effects of moisture on trapped mountain lee waves. $J$. Atmos. Sci., 39, 2490-2506

Turbulenzmessungen mit dem Forschungsflugzeug FALCON. To appear in Met. Rdsch.

Synoptic-scale atmospheric features and foehn. Contr. Atmos. Phys., 53, 486-507

Observation of a mountain wave event over the Pyrenees. Tellus 36A, 369-383

Experiments on stably and neutrally stratified flow over a model three-dimensional hill. J. Fluid Mech., 96, 671704

'An ALPEX aircraft atlas'. NCAR, Boulder, Co.

The dynamics of wave-induced downslope winds. J. Atmos. Sci., 32, 320-339

Numerical simulation of hydrostatic mountain waves. ibid., 35, 78-107

Lower turbulent zones associated with mountain lee waves. J. Appl. Met., 13, 54-61

Wave momentum flux-a GARP problem. Bull. Amer. Met. Soc., 53, 17-23

A severe downslope windstorm and aircraft turbulence event induced by a mountain wave. J. Atmos. Sci., 35, 59-77

Aircraft measurements of momentum flux over the Colorado Rocky Mountains. Quart. J. R. Met. Soc., 108, 625-642

Observations of a stationary mountain wave and its associated momentum flux and energy dissipation. J. Atmos. Sci., 30, 1135-1152

Mesoscale observations of upstream blocking. Quart. J. R. Met. Soc., 108, 427-434

Lee waves in a stratified flow. Part 4. Perturbation approximations. J. Fluid Mech., 35, 497

The evolution and stability of finite-amplitude mountain waves. Part II: Surface wave drag and severe downslope windstorms. J. Atmos. Sci., 36, 1498-1529

Nonlinear mountain waves in two and three spatial dimensions. Quart. J. R. Met. Soc., 109, 527-548

'The global atmospheric circulation'. Pp. 71-78 in Encyclopaedia of the Earth Sciences, Ed. R. W. Fairbridge, Reinhold Publ. Corp., New York

A measurement of mountain drag. J. Atmos. Sci. 35, 16441654

'Preliminary case study of airflow over and around the Alps'. GARP-ALPEX No. 7, Preliminary results, 97-107. Obtainable from WMO 